\title{
A ESTRUTURA A TERMO DE TAXAS DE JUROS NO BRASIL: MODELOS, ESTIMAÇÃO E TESTES
}

\author{
Sergio L. Franklin JR. * \\ Thiago B. Duarte ${ }^{\dagger}$ \\ César R. Neves $\ddagger^{\ddagger}$ \\ Eduardo F. L. Melo $\S$
}

\begin{abstract}
Resumo
Neste artigo, propomos uma metodologia para a construção da estrutura a termo da taxa de juros livre de risco no Brasil, usando o modelo de Svensson para interpolação e extrapolação das curvas de juros e algoritmos genéticos, em complemento aos algoritmos tradicionais de otimização não linear, para a estimação dos parâmetros do modelo. O objetivo é contribuir para que o mercado segurador brasileiro mensure suas obrigações descontando seus fluxos de caixa de maneira consistente e coerente, considerando a adoção, pela Superintendência de Seguros Privados (SUSEP), de padrões internacionais de supervisão de solvência e de reporte financeiro. Ao longo do artigo, apresentamos os resultados encontrados na modelagem das estruturas a termo de diferentes curvas de juros no Brasil.
\end{abstract}

Palavras-chave: Estrutura a termo; Taxas de juros; Interpolação; Extrapolação; Algoritmo genético; Nelson e Siegel; Svensson

JEL classification: G12, C51, C63

\begin{abstract}
In this paper, we propose a methodology for the construction of the risk-free interest rate term structure in Brazil, using the Svensson model for interpolation and extrapolation of the interest rate curves, and genetic algorithms, in complement to traditional algorithms of nonlinear optimization, for estimation of model parameters. The objective is to contribute to the Brazilian insurance market, so that insurance ces can appropriately measure their long-term obligations discounting cash flows in a manner that is consistent and coherent, considering the adoption of international standards of solvency supervision and financial reporting by the Superintendência de Seguros Privados (SUSEP). We present the results found in modeling the term structure of a number of interest rate curves in Brazil.
\end{abstract}

Palavras-chave: Term structure; Interest rates; Interpolation; Extrapolation; Genetic algorithm; Nelson and Siegel; Svensson.

\footnotetext{
${ }^{*}$ PUC-Rio

${ }^{\dagger}$ PUC-Rio

‡ PUC-Rio

$\S$ UERJ
} 


\section{Introdução}

O mercado segurador brasileiro ${ }^{1}$, principalmente o mercado de previdência e de seguros de sobrevivência, pelas características dos produtos ofertados, tem compromissos de longo prazo com seus segurados, participantes e assistidos. A regulação do setor ${ }^{2}$, por sua vez, estabelece que as seguradoras, resseguradores locais e entidades abertas de previdência complementar (EAPC) devem registrar esses compromissos futuros trazendo-os a valores presentes. Em função da convergência a padrões internacionais de supervisão de solvência e de reporte financeiro, em execução pela Superintendência de Seguros Privados (SUSEP), e a recente publicação da Circular SUSEP 410, de 22 de dezembro de 2010 (SUSEP 2010), as seguradoras, resseguradores locais e EAPCs devem testar a adequação de seus passivos, e para isso, precisam realizar estimativas correntes dos valores descontados dos seus fluxos de caixa, considerando premissas atuais, realistas e não tendenciosas para cada variável envolvida.

Um dos elementos mais relevantes para o cálculo da adequação de passivos é a estimação da estrutura a termo da taxa de juros (ETTJ) livre de risco, obtida a partir de instrumentos financeiros disponíveis no mercado brasileiro considerados isentos de risco de crédito. Os critérios de interpolação e extrapolação usados para derivar a ETTJ livre de risco devem ser fundamentados tecnicamente ou baseados em práticas amplamente adotadas pelo mercado financeiro. Em função desta demanda, apresentamos, neste artigo, um método de interpolação e extrapolação da ETTJ livre de risco para desconto dos compromissos futuros do mercado segurador brasileiro. Adicionalmente, o método poderá ser utilizado para cálculo dos capitais adicionais baseados nos riscos de mercado e de subscrição de seguros de vida e previdência.

A estrutura a termo da taxa de juros (ETTJ) é um conceito central da teoria financeira e econômica usado para precificar qualquer conjunto de fluxos de caixa (Fabozzi 2006, Ray 1992, Steven \& Kleinstein 1991). Ela é representada por um conjunto de pontos no espaço "taxa de juros" versus "prazo", onde cada ponto $(t, r(t))$ corresponde a uma taxa de juros $r(t)$, associada a um prazo (ou maturidade) $t$, taxa essa obtida com base em algum título negociado no mercado ${ }^{3}$.

A taxa de juros à vista (spot) associada a uma dada maturidade $\tau$ pode ser interpretada como o retorno de um título de renda fixa de cupom zero com vencimento em $\tau$. As taxas a termo (forward) são as taxas de juros implícitas pelas taxas à vista para períodos de tempo no futuro. A relação entre as duas pode ser ilustrada pelas fórmulas abaixo, a primeira usada para taxas compostas anualmente, e a segunda usada para taxas compostas continuamente:

$$
\begin{aligned}
\left(1+R_{t, t+T}^{t}\right)^{T} & =\prod_{k=0}^{T-1}\left(1+F R_{k}^{t}(1)\right) \\
e^{T \cdot y_{t}(T)} & =e^{\sum_{k=0}^{T-1} F R c_{k}^{t}(1)}
\end{aligned}
$$

Onde:

\footnotetext{
${ }^{1}$ Entende-se por mercado segurador brasileiro, para efeito deste artigo, o mercado de seguros, resseguro e previdência complementar.

${ }^{2}$ Pelo Conselho Nacional de Seguros Privados (CNSP) e pela Superintendência de Seguros Privados (SUSEP).

${ }^{3}$ Normalmente, um título de renda fixa ou derivativo de taxa de juros.
} 
- $R_{t, t+T}^{t}$ é a taxa à vista anual composta anualmente em $t$ para o período entre $t$ e $t+T$

- $y_{t}(T)$ é a taxa à vista anual composta continuamente (c.c.) em $t$ para o prazo $T$

- $F R_{k}^{t}(1)$ é a taxa a termo anual em $t$ para o período entre $t+k$ e $t+k+1$

- $F R c_{k}^{t}(1)$ é a taxa a termo anual c.c. em $t$ para o período entre os anos $t+k$ $\mathrm{e} t+k+1$

- $T(\in N)$ é o prazo de maturidade (medido em anos)

- $t$ é a data de avaliação da ETTJ (data de pregão)

Pode-se converter taxa contínua para taxa discreta aplicando as equações:

$$
\begin{gathered}
y_{t}(T)=\ln \left(1+R_{t, t+T}^{t}\right) \\
F R c_{k}^{t}(1)=\ln \left\{1+F R_{k}^{t}(1)\right\}
\end{gathered}
$$

A ETTJ pode ser descrita por uma curva de desconto $P_{t}(\tau)$, uma curva de taxas a termo $f_{t}(\tau)$, ou uma curva de taxas à vista $y_{t}(\tau)$, todas relacionadas entre si, de tal forma que, obtendo-se uma delas, chega-se facilmente às outras. As equações abaixo mostram como as funções desconto e taxas de juros a termo e à vista, em tempo contínuo, se relacionam entre si, e como, a partir de uma delas, pode-se obter todas as outras ${ }^{4}$.

$$
\begin{gathered}
P_{t}(\tau)=\exp \left\{-\tau \cdot y_{t}(\tau)\right\}=\exp \left\{-\int_{0}^{\tau} f_{t}(u) d u\right\} \\
f_{t}(\tau)=-\frac{1}{P_{t}(\tau)} \cdot P^{\prime}(\tau)=y_{t}(\tau)+\tau \cdot y_{t}^{\prime}(\tau) \\
y_{t}(\tau)=\frac{1}{\tau} \cdot \int_{0}^{\tau} f_{t}(u) d u=-\frac{1}{\tau} \cdot \ln P_{t}(\tau)
\end{gathered}
$$

Onde:

- $P_{t}(\tau)$ é o valor presente no instante $t$ de $\mathrm{R} \$ 1$ recebível em $t+\tau$

- $f_{t}(\tau)$ é a taxa a termo (instantânea) em $t$ para o prazo $\tau$

- $y_{t}(\tau)$ é a taxa à vista (composta continuamente) em $t$ para o prazo $\tau$

A ETTJ "livre de risco", também denominada "curva base ${ }^{5 ",}$ deve ser construída a partir de dados de mercado de títulos considerados isentos de riscos de crédito e liquidez 6 . Ao longo do tempo, a curva base pode oscilar de diferentes formas, em decorrência de choques diferenciados sobre as taxas de

\footnotetext{
${ }^{4}$ Apesar de na prática ser mais comum o uso de taxas discretas, a álgebra envolvendo equações matemáticas fica mais fácil quando se trabalha com taxas instantâneas e compostas continuamente.

${ }^{5}$ Pois exprime as taxas de juros mínimas para cada possível vencimento; os instrumentos financeiros livres de risco sujeitam seus detentores apenas ao risco de mercado.

${ }^{6}$ Os instrumentos de renda fixa, em geral, sujeitam os seus detentores a três tipos de risco financeiro: risco de mercado, risco de crédito e risco de liquidez.
} 
juros associadas a cada vencimento. É a variabilidade temporal da ETTJ que submete os instrumentos de renda fixa ao risco de mercado ${ }^{7}$.

Neste artigo, apresentamos um método para a construção da ETTJ livre de risco (no Brasil) para a taxa de juros pré-fixada (curva de taxas "pré") e para as taxas de cupom cambial, cupom de IPCA, cupom de IGPM e cupom de TR. Para a estimação dos parâmetros, foram usados um algoritmo tradicional de otimização não linear ${ }^{8}$ e um algoritmo genético especialmente desenvolvido para esta finalidade. Notamos que o uso do algoritmo genético permite reduzir o risco de falsa convergência ${ }^{9}$ e gera séries temporais mais estáveis para os parâmetros do modelo. O artigo propõe o uso do modelo de Svensson (Svensson 1994) para a interpolação e extrapolação (dentro de determinada faixa de prazos) da ETTJ livre de risco, e o uso de algoritmos genéticos, em complemento aos algoritmos tradicionais de otimização não linear, para a estimação dos parâmetros do modelo.

O restante deste trabalho está organizado da seguinte forma. A próxima seção descreve as bases de dados utilizadas para a construção das curvas de juros. A seção 3 descreve os modelos de estrutura a termo propostos por Nelson \& Siegel (1987) e Svensson (1994). A seção 4 descreve os métodos de otimização não linear usados para a estimação dos parâmetros da ETTJ. A seção 5 compara os resultados obtidos com cada método de estimação para a curva de cupom de IPCA, e apresenta a estimação dessa curva. A última seção conclui o trabalho. No anexo, estão mostrados os resultados da estimação para as demais curvas de juros.

\section{Base de Dados}

A escolha das bases de dados para a construção da ETTJ livre de risco passa necessariamente pela escolha dos instrumentos financeiros de mercado considerados isentos de riscos de crédito e liquidez. Para isso, a literatura internacional sugere o uso de cotações de mercado para os títulos de renda fixa emitidos pelo governo, teoricamente o emissor de menor risco de crédito da economia em razão de sua capacidade de tributar e/ou emitir moeda para pagar seus débitos. No mercado brasileiro, caracterizado pela escassez de instrumentos de renda fixa prefixada e pela baixa liquidez do mercado secundário, uma melhor representação da ETTJ livre de risco em reais pode ser construída com base nas taxas implícitas de instrumentos financeiros derivativos.

Em momentos de instabilidade econômica, as curvas de juros estimadas com base em títulos públicos federais e as estimadas com base em instrumentos financeiros derivativos podem diferir ${ }^{10}$. No entanto, em períodos de estabilidade econômica, observa-se que as duas curvas têm praticamente coincidido (Fraletti 2004). Com o aumento no número de negócios (e liquidez)

\footnotetext{
${ }^{7}$ Neste contexto, o risco de mercado incide somente sobre investimentos que têm horizontes de carregamento diferentes dos prazos dos títulos adquiridos.

${ }^{8}$ Método de otimização não linear Quasi-Newton.

${ }^{9} \mathrm{O}$ risco do algoritmo de otimização alcançar um ponto de mínimo (erro quadrático) local, e não o ponto de mínimo global.

${ }^{10} \mathrm{O}$ investimento em títulos públicos federais exige o comprometimento de recursos líquidos pelo prazo inteiro da aplicação. Já o investimento em derivativos envolve apenas a contratação de taxas, sem troca intertemporal de caixa, e apresenta um menor risco de liquidez (associado à incerteza do investidor quanto à própria necessidade de recursos líquidos ao longo do tempo).
} 
no mercado secundário de títulos públicos federais, que vem ocorrendo desde então, as duas curvas de juros devem se igualar.

O período de estudo deste trabalho vai do mês de setembro de 2003 até dezembro de 2010. A escolha da base de dados apropriada para cada curva de juros considera o instrumento financeiro livre de risco de maior liquidez no mercado, o número de vértices proporcionados por cada instrumento e o prazo do último ponto líquido de cada curva de juros. Não foi considerada a diferença de tributação incidente sobre o ganho de capital e juros, tampouco sobre os títulos com diferentes prazos de maturidade ${ }^{11}$.

Desta forma, para a curva de juros de cupom de IPCA foram usados os dados de mercado para as Notas do Tesouro Nacional - Série B (NTN-B), e para as curvas de taxas "pré", cupom cambial, cupom de IGPM e cupom de TR, foram usados dados/informações de mercado para instrumentos financeiros derivativos. Em ambos os casos, os dados de mercado foram coletados para o último dia útil de cada mês.

\subsection{Base de dados para a curva de cupom de IPCA}

A base de dados para a curva de cupom IPCA é formada pelos preços unitários das Notas do Tesouro Nacional - Série B (NTN-B), calculados pela Associação Brasileira das Entidades dos Mercados Financeiro e de Capitais (Anbima), segundo metodologia própria ${ }^{12}$, levando em conta não apenas as negociações realizadas entre os participantes do mercado, mas também os dados e as informações enviados diariamente por uma amostra selecionada de informantes/participantes do mercado ${ }^{13}$. Foram consideradas todas as Notas do Tesouro Nacional - Série B (NTN-B) que tiveram seus preços/taxas calculados pela Anbima.

As NTN-B são títulos pós-fixados que têm o seu valor nominal atualizado mensalmente, desde a data-base, pela variação do IPCA. Esses títulos pagam juros de cupom a cada semestre e resgatam o principal na data de vencimento. O mercado divulga a rentabilidade desses títulos, na forma de taxa efetiva anual, base 252 dias úteis. Com base nessa taxa, o preço (observado) de cada título (em $t$ ) é calculado de acordo com a seguinte relação ${ }^{14}$ :

$$
P_{N T N-B, i}=\sum_{j=1}^{k_{i}} \frac{1}{\left(1+R_{t, t+\tau_{j, i}}^{t}\right)^{\tau_{j, i} / 252}} \cdot F_{j, i}
$$

Onde:

- $P_{N T N-B, i}$ é o preço "observado" (calculado) da NTN-B de índice $i$

- $k_{i}$ é o número de pagamentos dessa NTN-B (inclui cupom e principal)

- $F_{j, i}$ é o j-ésimo pagamento dessa NTN-B

\footnotetext{
${ }^{11}$ Essas diferenças de tributação são difíceis de serem isoladas da amostra e não têm impacto significativo na ETTJ estimada.

${ }^{12}$ Detalhes da metodologia da Anbima podem ser encontrados no site http : //www.andima.com.br/comites/arqs/com_anexo_6.pdf.

${ }^{13}$ Esses dados são previamente submetidos a uma série de filtros, elaborados pela Anbima, com o objetivo de eliminar erros e distorções (erros de digitação, formato da taxa, horário na geração dos dados e/ou tentativa de manipulação das taxas).

${ }^{14}$ Essa equação pode ser facilmente deduzida aplicando-se a função de desconto (equação (5)) convertida para a forma discreta (equação (3)) para cada fluxo de caixa do título.
} 
- $\tau_{j, i}$ é o prazo (em dias úteis) em que ocorre o j-ésimo pagamento dessa NTN-B

- $R_{t, t+\tau_{j, i}}^{t}$ é a taxa efetiva anual, base 252 dias úteis, em $t$ para o período entre $t$ e $t+\tau_{j, i}$

\subsection{Base de dados para a curva de taxas "pré"}

A base de dados para a curva de taxas pré é formada pelas taxas referenciais "DI x PRÉ" da BM\&F ${ }^{15}$, calculadas com base nas cotações de ajuste dos contratos futuro DI de um dia. Foram consideradas as taxas referenciais BM\&F geradas para todos os prazos onde há vencimento de contrato futuro de DI, até o último vencimento com mais de 500 contratos realizados ${ }^{16}$.

No mercado futuro de DI de um dia da BM\&F, é negociada a taxa de juros efetiva anual, base 252 dias úteis, até o vencimento do contrato, definida pela acumulação das taxas diárias de DI no período compreendido entre a data de negociação e o último dia de negociação do contrato ${ }^{17}$. Os preços de ajuste diário são apurados no call eletrônico de fechamento, quando todos os negócios realizados no call para o mesmo vencimento são fechados por um único preço (fixing). Se não houver negócios no call, mas houver registro de ofertas, as mesmas serão aceitas, para efeito de apuração do preço de ajuste, se e somente se o tempo de exposição da oferta for maior ou igual a 30 segundos e a quantidade ofertada for maior ou igual a 100 contratos. Se não houver negociação e nem ofertas no call de fechamento, os preços de ajuste são arbitrados pela $\mathrm{BM} \& \mathrm{~F}$ usando modelos e metodologias por ela definidos ${ }^{18}$.

\subsection{Base de dados para a curva de cupom cambial}

A base de dados para a curva de cupom cambial é formada pelas taxas referenciais "cupom limpo" da BM\&F ${ }^{19}$, calculadas com base nas cotações de ajuste dos FRA ${ }^{20}$ de cupom cambial (FRC). Foram consideradas as taxas referenciais $\mathrm{BM} \& \mathrm{~F}$ geradas para todos os prazos onde há vencimento de contrato futuro de cupom cambial, até o último vencimento com mais de 100 contratos realizados.

O FRC é uma operação estruturada que negocia conjuntamente dois vencimentos de contrato futuro de cupom cambial (DDI) distintos: vencimento base com natureza inversa ao do FRC e vencimento mais longo de mesma

\footnotetext{
${ }^{15}$ Maiores informações sobre as taxas referenciais BM\&F podem ser encontradas no site $h t t p$ : $/ / w w w . b m f$ bovespa.com.br/shared/if rameBoletim.asp $x$ altura $=3000 \&$ idioma $=p t-b r \& u r l=$ www2.bmf.com.br/pages/portal/bmf bovespa/boletim $1 /$ T xRef 1 .asp .

${ }^{16}$ Para evitar erros com a introdução de informação distorcida, foram eliminados, em cada dia, os vencimentos pouco líquidos, definidos como aqueles com volume negociado inferior a 500 contratos (Leite et al. 2009).

${ }^{17}$ Taxa DI é a taxa média de depósitos interfinanceiros de um dia calculada pela Central de Custódia e de Liquidação Financeira de Títulos (Cetip).

${ }^{18}$ Para maiores detalhes sobre a metodologia de apuração dos preços de ajuste da BM\&F, acesse o site http : //www.bmf.com.br/bmf bovespa/pages/boletim1/arquivos/Metodologia_janeiro 2011.pdf.

${ }^{19}$ Maiores informações sobre as taxas referenciais BM\&F podem ser encontradas no site http://www.bmfbovespa.com.br/shared/iframeBoletim.aspx?altura=3000\&idioma=ptbr\&url=www2.bmf.com.br/pages/portal/bmfbovespa /boletim1/TxRef1.asp

${ }^{20}$ Forward rate agreement
} 
natureza e vencimento do FRC, garantindo o cupom cambial a termo. A negociação do FRC garante uma operação de cupom limpo, sem o efeito da defasagem de um dia da $\mathrm{PTAX}^{21}$ usada na liquidação dos contratos futuros de cupom cambial.

No FRA de cupom cambial da BM\&F é negociada a taxa de juros linear a termo, expressa ao ano com 360 dias corridos. Os preços de ajuste diário são apurados no call eletrônico de fechamento, quando todos os negócios realizados no call para o mesmo vencimento são fechados por um único preço (fixing). Se não houver negócios no call, mas houver registro de ofertas, as mesmas serão aceitas, para efeito de apuração do preço de ajuste, se e somente se o tempo de exposição da oferta for maior ou igual a 30 segundos e a quantidade ofertada for maior ou igual a 100 contratos. Se não houver negociação e nem ofertas no call de fechamento, os preços de ajuste são arbitrados pela BM\&F usando modelos e metodologias por ela definidos ${ }^{22}$.

\subsection{Base de dados para a curva de cupom de IGPM}

A base de dados para a curva de cupom de IGPM é formada pelas taxas referenciais "DI x IGPM" da BM\&F ${ }^{23}$, calculadas através de informações coletadas de participantes do mercado sobre os calls de swap do dia. Foram consideradas as taxas referenciais $\mathrm{BM} \& \mathrm{~F}$ geradas para todos os prazos onde há vencimento de contrato futuro de cupom de IGP-M.

O cupom de IGP-M é a taxa de juros efetiva anual, base 252 dias úteis, obtida a partir do cálculo da diferença entre a acumulação da taxa de DI1 no período compreendido entre a data da operação, inclusive, e a data de vencimento, exclusive, e a variação do IGP-M no período compreendido entre a data da operação, inclusive, e a data de vencimento, exclusive.

\subsection{Base de dados para a curva de cupom de TR}

A base de dados para a curva de cupom de TR é formada pelas taxas referenciais "DI x TR" da BM\&F ${ }^{24}$, calculadas através de informações coletadas de participantes do mercado sobre os calls de swap do dia. O cupom de TR é a taxa de juros efetiva anual, base 252 dias úteis, obtida a partir do cálculo da diferença entre a acumulação da taxa de DI1 no período compreendido entre a data da operação, inclusive, e a data de vencimento, exclusive, e a variação da TR no período compreendido entre a data da operação, inclusive, e a data de vencimento, exclusive.

\footnotetext{
${ }^{21}$ PTAX é uma taxa de câmbio, calculada ao final de cada dia pelo Banco Central do Brasil, que consiste na taxa média de todos os negócios com dólares realizados naquela data no mercado interbancário de câmbio. Normalmente, os contratos de derivativos de câmbio são liquidados com base na PTAX divulgada para o dia útil anterior.

${ }^{22}$ Para maiores detalhes sobre a metodologia de apuração dos preços de ajuste da BM\&F, acesse o site http://www.bmf.com.br/bmfbovespa/pages/boletim1/arquivos /Metodologia_janeiro2011.pdf.

${ }^{23}$ Maiores informações sobre as taxas referenciais BM\&F podem ser encontradas no site $h t t p$ : $/ / w w w . b m f$ bovespa.com.br/shared $/$ if rameBoletim.aspx?altura $=3000 \&$ idioma $=p t-b r \& u r l=$ www2.bmf.com.br/pages/portal/bmf bovespa/boletim $1 /$ T $x$ Ref 1 .asp

${ }^{24}$ Maiores informações sobre as taxas referenciais BM\&F podem ser encontradas no site http : $/ / w w w . b m f$ bovespa.com.br/shared $/$ if rameBoletim.aspx?altura $=3000 \&$ idioma $=p t-b r \& u r l=$ www2.bmf.com.br/pages/portal/bmf bovespa/boletim $1 /$ T $x$ Ref 1 .asp
} 


\section{Modelos de estimação da estrutura a termo da taxa de juros}

A ETTJ não é diretamente observável e precisa ser estimada a partir de cotações de mercado para títulos de renda fixa ou instrumentos financeiros derivativos, disponíveis para um número finito de vencimentos (os "dados/pontos observados da curva"). A partir deste conjunto discreto de dados, pode-se construir uma curva/função "contínua" que aproximadamente se "encaixe" nos dados observados, usando técnicas de interpolação, e estimar o valor da curva/função em pontos fora da zona conhecida, usando técnicas de extrapolação.

O procedimento mais comum para a estimação da estrutura a termo é impor, em um primeiro momento, uma forma funcional com $\mathrm{K}$ parâmetros para a função desconto $P_{t}(\tau)$, para a taxa à vista $y_{t}(\tau)$ ou para a taxa a termo $f_{t}(\tau)$. As formas funcionais podem ser polinômios (Chambers et al. 1984), splines (McCulloch 1975, Litzenberger \& Rolfo 1984, Fisher et al. 1995), funções exponenciais $^{25}$ (Nelson \& Siegel 1987, Svensson 1994), ou uma combinação destas ou outras funções ${ }^{26}$ (Smith \& Wilson 2001, Barrie \& Hibbert 2008). Em um segundo momento, os K parâmetros são estimados (minimizando a soma dos quadrados da diferença entre os dados estimados e observados da curva) ou determinados (montando um sistema de $\mathrm{K}$ equações a partir do qual os $\mathrm{K}$ parâmetros são calculados). Os métodos mais proeminentes e amplamente usados por diversos bancos centrais são os propostos por Nelson \& Siegel (1987), Svensson (1994).

\subsection{O modelo proposto por Nelson \& Siegel (1987)}

O modelo de Nelson e Siegel estabelece uma forma funcional de quatro parâmetros que procura aproximar a curva de taxas a termo por uma soma de funções exponenciais. É um modelo parametricamente parcimonioso capaz de gerar estruturas a termo com formatos muito semelhantes aos observados no mercado financeiro (curvas monotonicamente crescentes, decrescentes e com corcovas).

As taxas a termo $f_{t}(\tau)$ deste modelo são dadas pela equação:

$$
f_{t}(\tau)=\beta_{0, t}+\beta_{1, t} \cdot e^{-\lambda_{t} \cdot \tau}+\beta_{2, t} \cdot \lambda_{t} \cdot \tau \cdot e^{-\lambda_{t} \cdot \tau}
$$

As taxas à vista $y_{t}(\tau)$ podem ser calculadas, a partir das equações (7) e (9):

$$
y_{t}(\tau)=\beta_{0, t}+\beta_{1, t} \cdot\left(\frac{1-e^{-\lambda_{t} \cdot \tau}}{\lambda_{t} \cdot \tau}\right)+\beta_{2, t} \cdot\left(\frac{1-e^{-\lambda_{t} \cdot \tau}}{\lambda_{t} \cdot \tau}-e^{-\lambda_{t} \cdot \tau}\right)
$$

O parâmetro $\lambda_{t}$ mede a velocidade de decaimento da ETTJ: pequenos valores de $\lambda_{t}$ produzem um decaimento suave e, por isso, um melhor ajuste da curva para prazos mais longos da estrutura a termo; grandes valores de $\lambda_{t}$ produzem um decaimento mais rápido e um melhor ajuste para os prazos mais curtos. O parâmetro $\lambda_{t}$ também determina o prazo quando a carga em $\beta_{2, t}$ atinge o valor máximo.

\footnotetext{
${ }^{25}$ Svensson impõe uma forma paramétrica com 6 parâmetros; Nelson-Siegel impõe uma com 4 parâmetros.

${ }^{26}$ Smith-Wilson usa a soma de um termo exponencial para o comportamento assintótico de longo prazo da função desconto e uma combinação linear de $\mathrm{N}$ funções kernel (sendo $\mathrm{N}$ o número de dados/pontos observados na parte líquida da curva de juros); Barrie-Hibbert usa cubic splines para a parte líquida da curva de juros e Nelson-Siegel para a parte extrapolada.
} 
Os parâmetros $\beta_{0, t}, \beta_{1, t}, \beta_{2, t}$ podem ser interpretados como fatores dinâmicos latentes de longo, curto e médio prazo, respectivamente, da curva de taxas a termo, e os termos que multiplicam estes fatores são chamados de cargas de fatores:

- A carga que multiplica o parâmetro $\beta_{0, t}$ é igual a um, uma constante, e não decai a zero com o aumento do prazo de maturidade; $\beta_{0, t}$ pode ser visto como um fator de longo prazo.

- A carga que multiplica o fator $\beta_{1, t}$ é uma função que começa em um e decai rápida e monotonicamente a zero com o aumento do prazo de maturidade; $\beta_{1, t}$ pode ser visto como um fator de curto prazo: se $\beta_{1, t}<0$, a curva é crescente no curto prazo; se $\beta_{1, t}>0$ a curva é decrescente.

- A carga que multiplica o fator $\beta_{2, t}$ é uma função que começa em zero (e, portanto, não é de curto prazo), assume valores positivos no médio prazo, e decai a zero quando o prazo de maturidade tende ao infinito (e, portanto, não é de longo prazo); $\beta_{2, t}$ pode ser visto como um fator de médio prazo: se $\beta_{2, t}<0$, a curva tem uma corcova para baixo (formato de "U"); se $\beta_{2, t}>0$, a curva tem uma corcova para cima (formato de "U" invertido).

A Figura 1 ilustra as cargas de fatores e permite observar que, com uma escolha apropriada dos parâmetros do modelo, pode-se gerar uma variedade de curvas de taxas a termo com formas monotônicas e arqueadas. Os três parâmetros $\beta_{0, t}, \beta_{1, t}, \beta_{2, t}$ podem ser interpretados como fatores de nível, inclinação e curvatura, respectivamente (Diebold \& Li 2006).

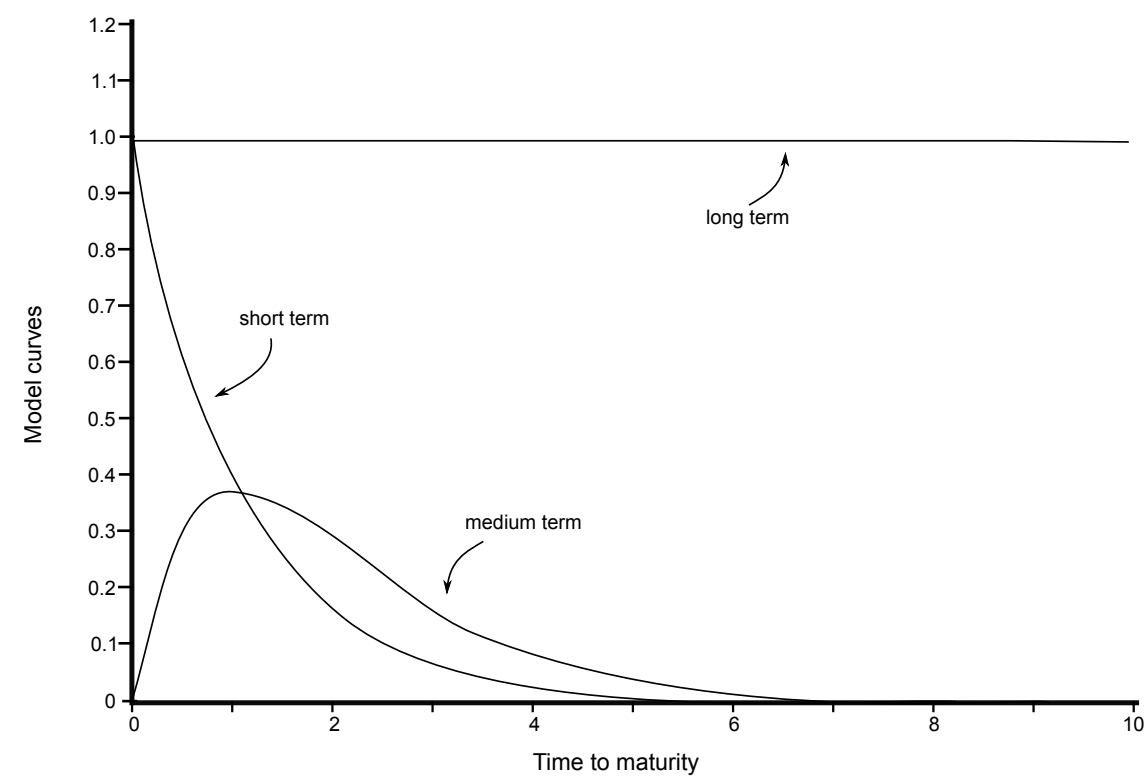

Figura 1: Componentes da curva de taxas a termo (Nelson \& Siegel 1987)

As taxas à vista de curto e longo prazo podem ser obtidas tomando-se o limite da equação (10) quando o prazo tende a zero ou infinito, respectivamente: 
$\lim _{\tau \rightarrow 0} y_{t}(\tau)=\beta_{0, t}+\beta_{1, t}$ e $\lim _{\tau \rightarrow \infty} y_{t}(\tau)=\beta_{0, t}$. A forma como ocorre a transição entre as taxas de curto e longo prazo é determinada pelos parâmetros $\beta_{2, t} \mathrm{e} \lambda_{t}$.

Para que a função $y_{t}(\tau)$ faça sentido econômico, o parâmetro $\lambda_{t}$ deve ser maior que zero. Além disso, para as curvas de taxas "pré" e cupom de IPCA, os parâmetros do modelo de Nelson e Siegel devem ainda satisfazer as seguintes restrições ${ }^{27}$ :

$$
\begin{aligned}
& \beta_{0, t}>0 \\
& \beta_{0, t}+\beta_{1, t}>0
\end{aligned}
$$

\subsection{O modelo proposto por Svensson (1994)}

O modelo proposto por Svensson estende o modelo de Nelson e Siegel com a adição de um novo termo exponencial à curva de taxas a termo, contendo dois parâmetros adicionais $\left(\beta_{3, t}\right.$ e $\left.\lambda_{2, t} ; \lambda_{2, t}>0\right)$, permitindo que se forme uma segunda corcova na forma da curva de juros ${ }^{28}$ :

$$
f_{t}(\tau)=\beta_{0, t}+\beta_{1, t} \cdot e^{-\lambda_{1, t} \cdot \tau}+\beta_{2, t} \cdot \lambda_{1, t} \cdot \tau \cdot e^{-\lambda_{1, t} \cdot \tau}+\beta_{3, t} \cdot \lambda_{2, t} \cdot \tau \cdot e^{-\lambda_{2, t} \cdot \tau}
$$

As taxas à vista $y_{t}(\tau)$ podem ser calculadas a partir das equações (7) e (11):

$$
\begin{aligned}
y_{t}(\tau)=\beta_{0, t}+\beta_{1, t} \cdot\left(\frac{1-e^{-\lambda_{1, t} \cdot \tau}}{\lambda_{1, t} \cdot \tau}\right) & +\beta_{2, t} \cdot\left(\frac{1-e^{-\lambda_{1, t} \cdot \tau}}{\lambda_{1, t} \cdot \tau}-e^{-\lambda_{1, t} \cdot \tau}\right) \\
& +\beta_{3, t} \cdot\left(\frac{1-e^{-\lambda_{2, t} \cdot \tau}}{\lambda_{2, t} \cdot \tau}-e^{-\lambda_{2, t} \cdot \tau}\right)
\end{aligned}
$$

Aqui, os fatores da estrutura a termo possuem a interpretação de nível (ou longo prazo), $\beta_{0, t}$, inclinação (ou curto prazo), $\beta_{1, t}$, e curvaturas (ou médio prazo), $\beta_{2, t}$ e $\beta_{3, t}$. Os parâmetros $\lambda_{1, t}$ e $\lambda_{2, t}$ caracterizam as velocidades de decaimento dos componentes de médio prazo da curva de juros, determinando onde as cargas que multiplicam os fatores $\beta_{2, t}$ e $\beta_{3, t}$ atingem seus valores máximos. O modelo de Svensson se torna idêntico ao modelo de Nelson e Siegel quando $\beta_{3, t}=0$ ou $\lambda_{1, t}=\lambda_{2, t}$.

Tomando os limites da equação acima, tem-se que $\lim _{\tau \rightarrow 0} y_{t}(\tau)=\beta_{0, t}+\beta_{1, t}$ (curto prazo) e $\lim _{\tau \rightarrow \infty} y_{t}(\tau)=\beta_{0, t}$ (longo prazo) ${ }^{29}$. Os parâmetros $\lambda_{1, t}$ e $\lambda_{2, t}$, associados com as funções exponenciais, capturam a velocidade de transição entre as taxas de curto e longo prazo e as distorções (corcovas) da curva.

Para que a função $y_{t}(\tau)$ faça sentido econômico, os parâmetros do modelo de Svensson devem satisfazer as seguintes restrições:

$$
\left\{\lambda_{1, t}>0 ; \lambda_{2, t}>0 ; \beta_{0, t}>0 ; \beta_{0, t}+\beta_{1, t}>0\right\}
$$

O modelo de Svensson propõe uma forma funcional simples para descrever toda a estrutura a termo da taxa de juros com apenas seis parâmetros. $\mathrm{O}$

\footnotetext{
${ }^{27}$ As taxas de juros nominais da economia são necessariamente positivas, e para um período de estabilidade econômica, como o período de estudo deste trabalho, as taxas de cupom de inflação (IPCA) devem ser também positivas.

${ }^{28}$ Por isso, nas situações onde a curva de taxas a termo apresenta uma forma mais complexa, o modelo de Svensson pode se mostrar significativamente superior ao modelo de Nelson e Siegel.

${ }^{29}$ Esse resultado vale também para o modelo de Nelson-Siegel.
} 
formato da equação permite uma estrutura suave e flexível que acomoda os diversos formatos de ETTJs observados na prática (Anbima 2010). Por isso, este modelo é muito usado para a interpolação das curvas de juros, podendo ser usado também para a extrapolação dessas curvas, dentro de determinada faixa de prazos, para além do último vértice disponível na base de dados ${ }^{30}$.

\section{Estimação dos parâmetros da estrutura a termo}

As curvas de juros foram estimadas adotando o modelo de Svensson e usando dois procedimentos distintos: (i) um método tradicional de otimização não linear (Quasi-Newton); (ii) uma combinação de algoritmo genético e método Quasi-Netwon.

A primeira etapa para a estimação dos parâmetros do modelo é definir se o objeto de estimação é o preço do título, a taxa de juros à vista ou a taxa a termo. Os preços dos instrumentos financeiros de curta maturidade são menos sensíveis a variações nas taxas de juros do que os de longa maturidade; pequenas alterações nos preços dos títulos de curto prazo implicam em grandes alterações nas taxas de juros, o contrário acontecendo para títulos de longo prazo. Por um lado, o procedimento de minimização da soma do erro quadrático das taxas de juros resulta em um resultado heterocedástico para os erros dos preços (erros elevados para os preços dos títulos de longo prazo). Por outro lado, o procedimento de minimização da soma do erro quadrático dos preços dos títulos resulta em um resultado heterocedástico para os erros das taxas à vista (erros elevados para as taxas à vista de curto prazo); uma abordagem para corrigir o problema de heterocedasticidade nas taxas à vista é ponderar o erro quadrático do preço de cada título pelo inverso da duration de Macaulay, dando mais relevância para os erros dos títulos de curto prazo.

Dependendo do objeto de estimação, os resíduos/erros nos preços e nas taxas podem ser homocedásticos ou heterocedásticos: se o objeto de estimação for o preço do título, os resíduos serão homocedásticos nos preços e heterocedásticos nas taxas; se o objeto de estimação for a taxa de juros à vista, os resíduos/erros serão homocedásticos nas taxas e heterocedásticos nos preços ${ }^{31}$.

- Se o objeto de estimação for o preço do título, a função desconto $P_{t}(\tau)$ é estimada, para cada data de pregão, de tal forma a minimizar a soma dos quadrados dos erros dos preços (estimados e observados) de um conjunto de títulos públicos federais "livres de riscos". Ou seja, para um determinado conjunto de parâmetros (solução inicial), a função desconto é usada para calcular o preço estimado de cada título, de acordo com a equação (5), e executa-se um algoritmo de otimização com o objetivo de minimizar a soma dos quadrados dos erros entre os preços estimados e observados dos títulos públicos.

- Se o objeto de estimação for a taxa de juros, a função taxa à vista $y_{t}(\tau)$ é estimada, para cada data de pregão, de tal forma a minimizar a soma dos quadrados dos erros das taxas à vista (estimadas e observadas) "livres de risco". Ou seja, para um determinado conjunto de parâmetros (solução

\footnotetext{
${ }^{30}$ A base de dados usada para a curva de cupom de IPCA, por exemplo, contém títulos com maturidades de até 40 anos.

${ }^{31} \mathrm{Em}$ geral, deseja-se para a ETTJ um resultado que seja homocedástico nas taxas de juros - o que implica em heterocedasticidade nos preços.
} 
inicial), a taxa à vista é estimada para cada ponto observado da curva de juros, de acordo com a equação do modelo ${ }^{32}$, e executa-se um algoritmo de otimização com o objetivo de minimizar a soma dos quadrados dos erros entre as taxas estimadas e observadas para os pontos/dados observados da curva de juros.

Portanto, para a construção das curvas de taxas "pré", cupom cambial, cupom de IGPM e cupom de TR, onde foram usados dados e informações do mercado de derivativos, o objeto de estimação é a taxa de juros, enquanto que para a curva de juros de cupom de IPCA, onde foram usados preços de mercado das NTN-B, o objeto de estimação é o preço de cada título (com o erro quadrático ponderado pelo inverso da duration).

\subsection{Métodos tradicionais de otimização não linear}

Um problema genérico de otimização não linear consiste em encontrar um vetor $\bar{\phi}$ que maximize (ou minimize) uma função $f(\bar{\phi}), \bar{\phi}=\left[\phi_{1}, \phi_{2}, \ldots \phi_{q}\right]^{T} \in$ $\operatorname{Re}^{q}$, sujeito a uma série de restrições expressas na forma:

$$
\begin{aligned}
& c_{i}(\bar{\phi})=0, i=1, \ldots, p \\
& c_{i}(\bar{\phi}) \geq 0, i=p+1, \ldots, n
\end{aligned}
$$

Para a estimação dos parâmetros do modelo de Svensson ${ }^{33}$ foram consideradas duas formulações distintas para o problema de otimização não linear:

1. Para a curva de juros de cupom de IPCA ${ }^{34}$, a função objetivo que se quer minimizar é dada por $^{35}$ :

$$
\text { FOBJ }: \operatorname{Min}\left\{\sum_{i=1}^{N_{t}} w_{i} \cdot\left(P_{N T N-B, i}-\sum_{j=1}^{k_{i}} \exp \left[-\tau_{j, i} \cdot y_{t}\left(\tau_{j, i}\right)\right] \cdot F_{j, i}\right)^{2}\right\}
$$

Onde:

- $P_{N T N-B, i}$ é o preço "observado" da NTN-B de índice $i$

- $k_{i}$ é o número de pagamentos da NTN-B $i$ (inclui cupom e principal)

- $F_{j, i}$ é o j-ésimo pagamento da NTN-B $i$

- $\tau_{j, i}$ é o prazo (em dias úteis) em que ocorre o j-ésimo pagamento da NTN-B $i$

- $N_{t}$ é o número de NTN-B negociadas/observadas na data de pregão $(t)$

\footnotetext{
${ }^{32}$ Equações (10) e (12) para os modelos Nelson-Siegel e Svensson, respectivamente.

${ }^{33}$ Note que o modelo de Nelson e Siegel pode ser visto como um caso particular do modelo de Svensson quando $\beta_{3, t}=0$ ou $\lambda_{1, t}=\lambda_{2, t}$.

${ }^{34}$ Onde foram usados dados de mercado das NTN-B e o objeto de estimação foi o preço de cada título ponderado pelo inverso da duration.

${ }^{35}$ Para simplificar a notação, o índice $t$ (referente à data de pregão/negociação do título) foi suprimido para a maioria dos termos da função objetivo; o índice foi mantido apenas nas situações onde a sua omissão prejudicaria a compreensão do texto.
} 
- $y_{t}\left(\tau_{j, i}\right)$ é a taxa à vista estimada na data $t$ para o prazo entre $t$ e $t+\tau_{j, i}$ (para o modelo de Svensson, veja a equação (12))

- $w_{i}$ é o inverso da duration da NTN-B $i\left(w_{i}=1 /\right.$ duration $\left._{i}\right)$

2. Para as curvas de taxas "pré", cupom cambial, cupom de IGPM e cupom de $\mathrm{TR}^{36}$ a função objetivo que se quer minimizar é dada por:

$$
\text { FOBJ : Min }\left\{\sum_{i=1}^{M_{t}}\left(\operatorname{TxRe} f_{t}\left(\tau_{i}\right)-y_{t}\left(\tau_{i}\right)\right)^{2}\right\}
$$

Onde:

- $T x \operatorname{Re} f_{t}\left(\tau_{i}\right)$ é a taxa à vista referencial na data $t$ para o prazo entre $t$ e $t+\tau_{i}$ (conforme descrito na seção 2 do artigo em "bases de dados")

- $y_{t}\left(\tau_{i}\right)$ é a taxa à vista estimada na data $t$ para o prazo entre $t$ e $t+\tau_{i}$ (para o modelo de Svensson, veja a equação (12))

- $M_{t}$ é o número de taxas referenciais usadas (base de dados) na data de pregão $(t)$

Em ambos os casos, os parâmetros do modelo de Svensson devem satisfazer as restrições apresentadas na equação (13).

Em geral, os algoritmos tradicionais de otimização não linear não garantem que o ótimo global do problema seja encontrado. Ao invés disso, tem-se, na maioria das vezes, apenas um ótimo local ${ }^{37}$ (Bertsekas 1999). Em particular, a alta não linearidade das funções em (14) e (15) faz com que o risco de falsa convergência (quando o algoritmo de otimização encontra um mínimo local, que não é o mínimo global) seja elevado, e o resultado da otimização fica muito sensível aos valores iniciais empregados (solução inicial viável).

\subsection{Algoritmos genéticos}

Os algoritmos genéticos (AG), introduzidos por Holland (1975), são algoritmos de busca baseados em mecanismos de seleção natural e genética, e constituem técnicas heurísticas de otimização "global". Eles precisam ter três características, também chamadas de operadores genéticos: seleção, recombinação (cross-over) e mutação (Mitchell 1998). Trata-se de um método alternativo de otimização não linear que tende a se tornar bastante popular com o avanço da velocidade computacional.

A construção do AG começa com a criação de uma representação cromossomial. A representação mais comum é a codificação binária (Dawid (1999), Arifovic \& Gencay (2000)) e está baseada na decomposição de cada número em um código de cadeia binária ${ }^{38}$. Uma representação cromossomial alternativa é a codificação real, proposta por Davis (1989), que é a representação mais

\footnotetext{
${ }^{36}$ Onde foram usados dados/informações do mercado de derivativos e o objeto de estimação foi a taxa de juros.

${ }^{37}$ Somente quando a função objetivo e as restrições do problema satisfazem determinadas propriedades específicas é que se pode garantir o alcance do ótimo global de um problema de otimização não linear.

${ }^{38}$ A analogia com a genética é imediata: um cromossomo é uma sequência de genes; na representação binária, cada gene corresponde a um bit (que pode assumir os valores zero ou um). $\mathrm{O}$ conceito representado por cada bit e conjunto de bits é inerente à representação adotada pelo AG.
} 
apropriada para problemas de otimização de parâmetros com valores no domínio contínuo (Davis 1991, Wright 1991, Eshelman \& Shaffer 1993, Herrera et al. 1998).

Neste trabalho foi usada a codificação real, onde cada cromossomo é um vetor de números reais, e cada elemento desse vetor (gene) representa uma variável do problema de otimização. Foi desenvolvido um algoritmo genético em SPlus v.8.1 especificamente voltado para a estimação dos parâmetros do modelo de Svensson ${ }^{39}$. Este AG tomou como base o trabalho de Gimeno \& Nave (2006) do Banco Central da Espanha, e introduziu um novo operador de mutação (evolucionário), com o objetivo de ampliar o espaço de busca para o alcance da solução ótima global, e novos parâmetros de inicialização, para adequar o algoritmo de busca às características do problema em questão. O projeto de desenvolvimento deste AG teve como objetivo explorar a informação acumulada em cada iteração e orientar as buscas subsequentes do algoritmo para subespaços apropriados em busca da solução (ou região) ótima global. O fluxograma da Figura 2 ilustra o funcionamento do AG.

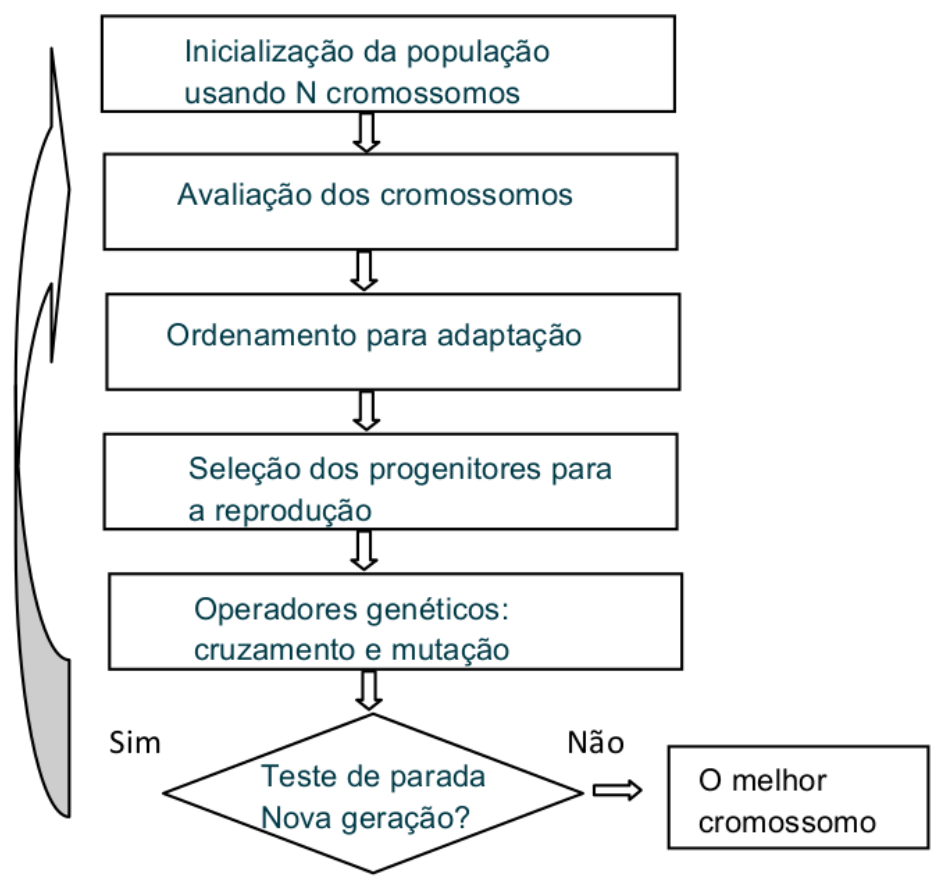

Figura 2: Fluxograma de funcionamento do AG

As populações de indivíduos (cromossomos) são criadas e submetidas aos operadores genéticos. Cada cromossomo é avaliado, segundo uma função que avalia o grau de adequação deste cromossomo como potencial solução para o problema de otimização. Os cromossomos são ordenados e os progenitores selecionados aleatoriamente segundo uma função distribuição de probabilidade, que atribui maior probabilidade de recombinação para os cromossomos melhor avaliados. Os operadores de recombinação e mutação entram em ação para compor os cromossomos "filhos" e introduzir diversidade (aleatória) nos

\footnotetext{
${ }^{39} \mathrm{O}$ modelo de Nelson e Siegel pode ser visto como um caso particular do modelo de Svensson.
} 
seus genes. Novas gerações são criadas e avaliadas. O AG processa cada geração de cromossomos, que representa o espaço de busca de soluções, e usa os três operadores genéticos (seleção, recombinação e mutação) de forma a "evoluir" iterativamente as soluções viáveis em busca da solução ótima do problema de otimização.

Os algoritmos evolucionários ${ }^{40}$, em geral, não asseguram a obtenção do melhor resultado possível em todas as suas execuções. Eles são bons para varrer o espaço viável em busca da solução ótima, mas apresentam dificuldades inerentes para a realização do "ajuste fino local", ou seja, para encontrar o ponto de ótimo local dentro da região de ótimo global ${ }^{41}$. Por isso, neste trabalho, foi usada uma combinação do algoritmo genético com um algoritmo tradicional de otimização não linear (Quasi-Newton) para a estimação das curvas de juros.

\section{Representação cromossomial}

A representação cromossomial adotada considera cada indivíduo / cromossomo um candidato a solução do problema de otimização, onde cada cromossomo é um vetor de seis números reais $\left(\bar{\phi} \in \mathfrak{R e}^{6}\right)$, e cada elemento desse vetor (gene) representa o valor atribuído a um parâmetro do modelo de Svensson ${ }^{42}$.

Uma geração da população consiste de $N$ cromossomos e corresponde a uma iteração do AG. Desta forma, os $N$ indivíduos da k-ésima geração da população podem ser assim representados ${ }^{43}$ :

$$
\begin{aligned}
& \bar{\phi}_{i}^{k}=\left[\begin{array}{llllll}
\beta_{0, i}^{k} & \beta_{1, i}^{k} & \beta_{2, i}^{k} & \beta_{3, i}^{k} & \lambda_{1, i}^{k} & \lambda_{2, i}^{k}
\end{array}\right]^{T} \\
& (i=1, \ldots, N) \\
& (k=1,2, \ldots)
\end{aligned}
$$

Inicialização da população

A inicialização da população começa com a geração de $N$ indivíduos/cromossomos, a partir de variações aleatórias produzidas sobre o cromossomo gerador da espécie $\left(\bar{\phi}^{*}\right)$, formando assim a primeira geração da população $(k=1)$.

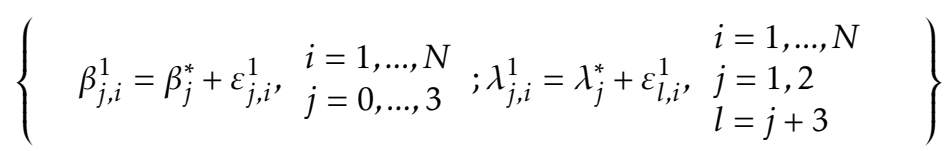

Onde:

- $\beta_{j}^{*}$ e $\lambda_{j}^{*}$ são os valores atribuídos aos genes do cromossomo gerador da espécie

$$
\text { - } \varepsilon_{j, i}^{1} \sim N\left(0, \sigma_{j}^{0}\right) \text {. }
$$

\footnotetext{
${ }^{40}$ Os algoritmos genéticos são um ramo dos algoritmos evolucionários.

${ }^{41}$ Holland (1975) sugere que o AG deve ser usado como um pré-processador para realizar uma busca inicial, antes de passar o processo de busca para um sistema que pode empregar conhecimento de domínio para guiar a busca local.

${ }^{42}$ Os genes são, portanto, as variáveis do problema de otimização, e o cromossomo/indivíduo (conjunto de genes) é um candidato à solução ótima (uma solução viável).

${ }^{43}$ Neste trabalho, $\mathrm{N}=1.000$.
} 
A população inicial pode ser representada em notação matricial da seguinte maneira:

- Cromossomo gerador da espécie:

$$
\bar{\phi}^{*}=\left[\begin{array}{llllll}
\beta_{0}^{*} & \beta_{1}^{*} & \beta_{2}^{*} & \beta_{3}^{*} & \lambda_{1}^{*} & \lambda_{2}^{*}
\end{array}\right]^{T}
$$

- Vetor aleatório:

$$
\begin{aligned}
& \bar{\varepsilon}_{i}^{1}=\left[\begin{array}{llllll}
\varepsilon_{0, i}^{1} & \varepsilon_{1, i}^{1} & \varepsilon_{2, i}^{1} & \varepsilon_{3, i}^{1} & \varepsilon_{4, i}^{1} & \varepsilon_{5, i}^{1}
\end{array}\right]^{T} \\
& (i=1, \ldots, N)
\end{aligned}
$$

- A primeira geração de $\mathrm{N}$ indivíduos:

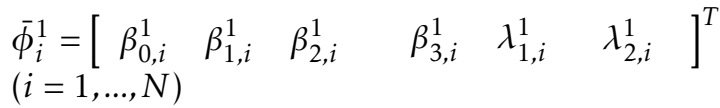

$$
\begin{aligned}
& \bar{\phi}_{i}^{1}=\bar{\phi}^{*}+\bar{\varepsilon}_{i}^{1}|o u\rangle\left[\begin{array}{c}
\beta_{0, i}^{1} \\
\beta_{1, i}^{1} \\
\beta_{2, i}^{1} \\
\beta_{3, i}^{1} \\
\lambda_{1, i}^{1} \\
\lambda_{2, i}^{1}
\end{array}\right]=\left[\begin{array}{c}
\beta_{0}^{*} \\
\beta_{1}^{*} \\
\beta_{2}^{*} \\
\beta_{3}^{*} \\
\lambda_{1}^{*} \\
\lambda_{2}^{*}
\end{array}\right]+\left[\begin{array}{c}
\varepsilon_{0, i}^{1} \\
\varepsilon_{1, i}^{1} \\
\varepsilon_{2, i}^{1} \\
\varepsilon_{3, i}^{1} \\
\varepsilon_{4, i}^{1} \\
\varepsilon_{5, i}^{1}
\end{array}\right]
\end{aligned}
$$

Para ampliar o espaço de busca e reduzir o número de iterações do AG, os cromossomos iniciais (geradores da espécie) foram selecionados por dois procedimentos complementares: o primeiro, baseado em dados passados, utiliza como valores iniciais os valores ótimos estimados para os parâmetros da ETTJ do último dia útil do mês anterior; o segundo, baseado em dados correntes, utiliza como valores iniciais as informações sobre taxas de juros de títulos públicos federais na data de cada pregão ${ }^{44}$. A metade dos indivíduos foi gerada por cada procedimento.

Foram, portanto, criados dois cromossomos iniciais $\left(\bar{\phi}^{* 1}\right.$ e $\left.\bar{\phi}^{* 2}\right)$, e a primeira geração de indivíduos foi composta de:

$$
\begin{aligned}
& \left\{\bar{\phi}_{i}^{1}=\bar{\phi}^{* 1}+\bar{\varepsilon}_{i}^{1} ; i=1, \ldots \frac{N}{2}\right\} \\
& \left\{\bar{\phi}_{i}^{1}=\bar{\phi}^{* 2}+\bar{\varepsilon}_{i}^{1} ; i=\frac{N}{2}+1, \ldots N\right\}
\end{aligned}
$$

Os termos aleatórios usados para a inicialização da população $\left(\varepsilon_{j, i}\right)$ permitem introduzir diversidade na população inicial e calibrar a magnitude das mutações em gerações futuras. O desvio padrão $\sigma_{j}^{0}$ do termo aleatório associado a cada gene $(j)$ depende do valor inicial atribuído ao gene e de um

\footnotetext{
${ }^{44}$ Para este segundo procedimento, $\beta_{0}^{*}$ é a taxa interna de retorno (TIR) do título público de maior maturidade, $\beta_{1}^{*}$ é a diferença entre a TIR do título de menor maturidade e a TIR do título de maior maturidade, $\beta_{2}^{*}=\beta_{3}^{*}=0$ (curvas de juros sem corcovas) e $\lambda_{1}^{*}$ e $\lambda_{2}^{*}$ são mesmos valores adotados no primeiro procedimento.
} 
parâmetro $\sigma$ usado para calibrar o modelo. ${ }^{45}$

Para os cromossomos gerados a partir de $\bar{\phi}^{* 1}$ foi usado:

$$
\begin{gathered}
\sigma_{0}^{0}=\sigma_{1}^{0}=\sigma \cdot \beta_{0}^{* 1}, \quad \sigma_{2}^{0}=\sigma \cdot\left|\beta_{2}^{* 1}\right|, \quad \sigma_{3}^{0}=\sigma \cdot\left|\beta_{3}^{* 1}\right| \\
\sigma_{4}^{0}=\sigma \cdot \lambda_{1}^{* 1}, \quad \sigma_{5}^{0}=\sigma \cdot \lambda_{2}^{* 1}
\end{gathered}
$$

Para os cromossomos gerados a partir de $\bar{\phi}^{* 2}$ foi adotado:

$$
\sigma_{0}^{0}=\sigma_{1}^{0}=\sigma \cdot \beta_{0}^{* 2}, \quad \sigma_{2}^{0}=\sigma_{3}^{0}=\sigma \cdot\left|\beta_{1}^{* 2}\right|, \quad \sigma_{4}^{0}=\sigma \cdot \lambda_{1}^{* 1}, \quad \sigma_{5}^{0}=\sigma \cdot \lambda_{2}^{* 1}
$$

Quanto maior o desvio padrão $(\sigma)$, maiores são a diversidade da população inicial e a magnitude das mutações: um pequeno valor de $\sigma$ aumenta o risco de falsa convergência (quando o algoritmo encontra um mínimo local e não global); um grande valor de $\sigma$ aumenta o espaço de busca e o número de iterações necessárias para o alcance do mínimo global.

Foram realizadas simulações do AG para diferentes valores de $\sigma$, e o valor selecionado para a construção de cada curva de juros levou em conta o valor ótimo da função objetivo (valor mínimo da soma dos quadrados dos erros) e o número de iterações (gerações) necessárias para o alcance do mínimo ${ }^{46}$. Como ilustração, o valor de $\sigma$ para a curva de cupom de IPCA $^{47}$ foi selecionado a partir das simulações apresentadas na Figura 3.
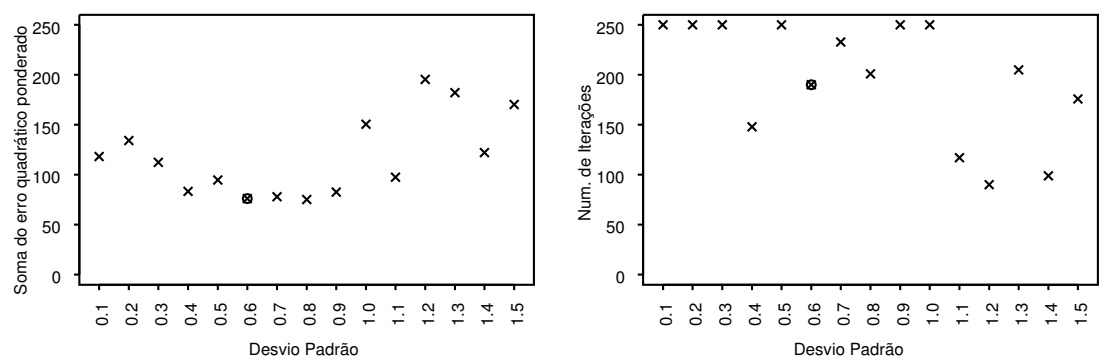

Figura 3: Simulações do AG para diferentes valores de $\sigma$ para o dia 30/12/2010 (curva de cupom de IPCA)

Nem todo cromossomo gerado aleatoriamente é uma solução válida/viável para o problema de otimização. Para que um cromossomo seja viável, ele precisa satisfazer as condições expressas em (13). O AG, portanto, testa se cada um dos cromossomos gerados $(i=1, \ldots, N)$ satisfaz as condições de viabilidade, e, caso não satisfaça, gera novos valores aleatórios para os respectivos parâmetros (genes), até que se obtenha uma geração inicial com $N$ cromossomos viáveis.

\footnotetext{
${ }^{45} \mathrm{O}$ impacto de $\sigma$ sobre a magnitude da mutação será visto mais adiante.

${ }^{46}$ Para fins de calibragem dos parâmetros do $\operatorname{AG}(\sigma, \eta, \alpha, \pi)$, o número de iterações foi limitado a 250, e a prioridade de seleção foi dada para os parâmetros que geraram a menor soma dos erros quadráticos ponderados em 30/12/2010 (data de calibragem do AG).

${ }^{47} \mathrm{O}$ valor selecionado de $\sigma$ (após as simulações) foi de 0,6 para a curva de cupom de IPCA.
} 


\section{Seleção}

Nesta fase, o AG seleciona, para uma dada geração $(k)$, os indivíduos (cromossomos) de maior qualidade e mais apropriados para a reprodução. Para isso é necessário definir uma medida que vai quantificar a "qualidade" de cada um dos $N$ cromossomos desta geração.

Uma medida natural para se avaliar a qualidade de um cromossomo, como candidato à solução do problema de otimização, é o próprio valor medido da função objetivo (dado pelas equações (14) e (15) da seção 4.1), substituindo os parâmetros do modelo de Svensson pelos respectivos genes de cada cromossomo. Quanto menor o valor da função objetivo, melhor é o ajuste do modelo aos dados observados. Neste trabalho, esta medida de qualidade é chamada de "índice de mortalidade" (IM ) do cromossomo, de tal forma que, quanto menor o IM , melhor é a qualidade do cromossomo, e maior é a sua chance de sobrevivência (e reprodução), de forma análoga ao processo de seleção natural bem caracterizado pela expressão "survival of the fit enough" (Scott 2009).

Portanto:

1. Para a curva de juros de cupom de IPCA, o índice de mortalidade de um cromossomo é dado por:

$$
I M=\left\{\sum_{i=1}^{N_{t}} w_{i} \cdot\left(P_{N T N-B, i}-\sum_{j=1}^{k_{i}} \exp \left[-\tau_{j, i} \cdot y_{t}\left(\tau_{j, i}\right)\right] \cdot F_{j, i}\right)^{2}\right\}
$$

2. Para as curvas de taxas "pré", cupom cambial, cupom de IGPM e cupom de TR, o índice de mortalidade de um cromossomo é dado por:

$$
I M=\left\{\sum_{i=1}^{M_{t}}\left(T x \operatorname{Ref} f_{t}\left(\tau_{i}\right)-y_{t}\left(\tau_{i}\right)\right)^{2}\right\}
$$

O AG então cria uma lista de cromossomos, ordenando-os conforme o valor de seu $I M$ (do menor para o maior valor), e seleciona um número $M=N . \eta$ de cromossomos sobreviventes, onde $\eta$ é o percentual de cromossomos que deve sobreviver em cada geração/iteração do algoritmo: um valor muito baixo de $\eta$ pode fazer o processo de convergência ficar muito lento; um valor muito alto de $\eta$ aumenta o risco de falsa convergência.

Foram realizadas simulações do AG para diferentes valores de $\eta$, e o valor selecionado para a construção de cada curva de juros levou em conta o valor ótimo da função objetivo (valor mínimo da soma dos quadrados dos erros) e o número de iterações (gerações) necessárias para o alcance do mínimo. Como ilustração, o valor de $\eta$ para a curva de cupom de IPCA $^{48}$ foi selecionado a partir das simulações apresentadas na Figura 4.

Dessa forma, se a lista ordenada de cromossomos sobreviventes da geração $k$ (antes do operador de seleção) era $\left\{\bar{\phi}_{1}^{k}, \bar{\phi}_{2}^{k}, \ldots, \bar{\phi}_{M}^{k}, \bar{\phi}_{M+1}^{k}, \ldots, \bar{\phi}_{N}^{k}\right\}$, após o operador de seleção, a lista de cromossomos é reduzida a $\left\{\bar{\phi}_{1}^{k+1}, \bar{\phi}_{2}^{k+1}, \ldots, \bar{\phi}_{M}^{k+1}\right\}$ e os operadores de recombinação e mutação entram em ação com o objetivo de melhorar os cromossomos da geração subsequente $(k+1)$ e evoluir a solução viável na direção do ótimo global do problema de otimização.

${ }^{48} \mathrm{O}$ valor selecionado para $\eta$ (após as simulações) foi de $50 \%$ para a curva de cupom de IPCA. 

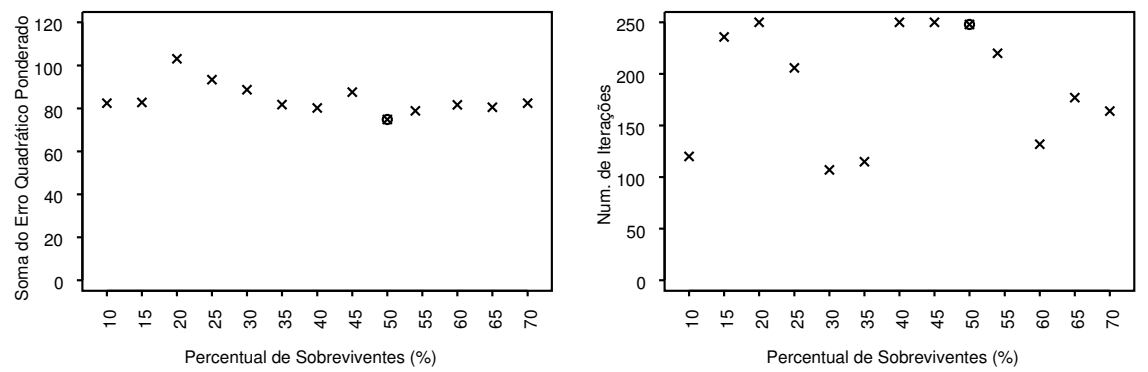

Figura 4: Simulações do AG para diferentes valores de $\eta$ para o dia 30/12/2010 (curva de cupom de IPCA)

\section{Recombinação}

O operador de recombinação atua primeiro, adicionando $N .(1-\eta)$ novos cromossomos à geração $k+1$ da população. Para isso, ele seleciona os cromossomos progenitores ( $r$ e $s$ ) da geração $k$, atribuindo uma maior probabilidade de seleção aos cromossomos com menor IM (melhor qualidade). É gerada uma amostra aleatória $\left\{\xi_{i}, i=1,2, \ldots, 2 . N .(1-\eta)\right\}$ de uma variável aleatória $\xi$ com distribuição $\operatorname{Beta}(1, \alpha)$ e, para cada par distinto de elementos da amostra, são calculados os índices de ordenamento dos cromossomos progenitores, fazendo $r=\xi_{i}$.N e $s=\xi_{j} . N(i \neq j)$. Cada gene do cromossomo filho $\left(\bar{\phi}_{q}^{k+1}\right.$ ) é então gerado por uma combinação linear dos respectivos genes dos dois cromossomos progenitores. Ou seja:

$$
\bar{\phi}_{q}^{k+1}=D_{6 \times 6} \cdot \bar{\phi}_{r}^{k}+\left(\mathrm{I}_{6}-D_{6 \times 6}\right) \cdot \bar{\phi}_{s}^{k}
$$

Onde:

- $D_{6 x 6}$ é uma matriz diagonal de dimensão 6 , onde $d_{i, j}=\left\{\begin{array}{l}\psi_{i}, \text { se } i=j \\ 0, \text { c.c. }\end{array}\right.$

- $\bar{\psi}$ é um vetor coluna de tamanho 6, gerado por variáveis aleatórias independentes e identicamente distribuídas com distribuição uniforme no intervalo $[0,1]$.

- $\mathrm{I}_{6}$ é a matriz identidade.

Note que $\xi \sim \operatorname{Beta}(1, \alpha)$ é uma variável aleatória real contínua que pode assumir valores no intervalo [0,1], e quanto maior o valor de $\alpha$, maior é a probabilidade de escolha dos progenitores de menor IM (melhor qualidade). A Figura 5 abaixo mostra a função densidade de probabilidade da distribuição $\operatorname{Beta}(1, \alpha)$ para três valores distintos de $\alpha$.

O parâmetro $\alpha$ pode ser interpretado como um índice de atratividade concedido aos cromossomos com melhores genes: um valor baixo de $\alpha$ (por exemplo, $\alpha=1$ ) indica que não há predileção aos cromossomos de melhor qualidade, o que pode fazer o processo de convergência ficar muito lento; um valor muito alto de $\alpha$ reduz a diversidade em cada geração e aumenta o risco de falsa convergência.

Foram realizadas simulações do AG para diferentes valores de $\alpha$, e o valor selecionado para a construção de cada curva de juros levou em conta o valor ótimo da função objetivo (valor mínimo da soma dos quadrados dos erros) e o número de iterações (gerações) necessárias para o alcance do mínimo. Como 
$\alpha=1$

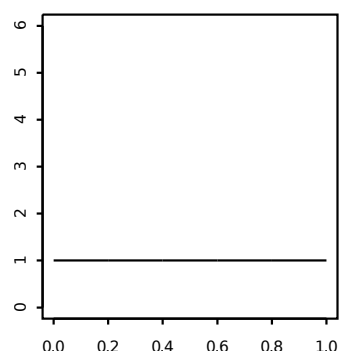

$\alpha=3$

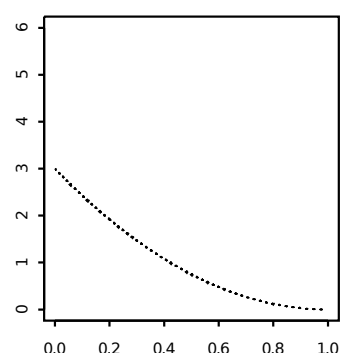

$\alpha=6$

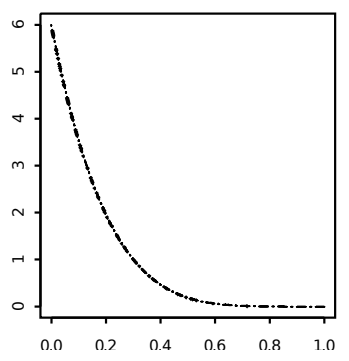

Figura 5: Exemplos da distribuição $\operatorname{Bet} a(1, \alpha)$ para $\alpha=1,3$ e 6

ilustração, o valor de $\alpha$ para a curva de cupom de IPCA ${ }^{49}$ foi selecionado a partir das simulações apresentadas na Figura 6.
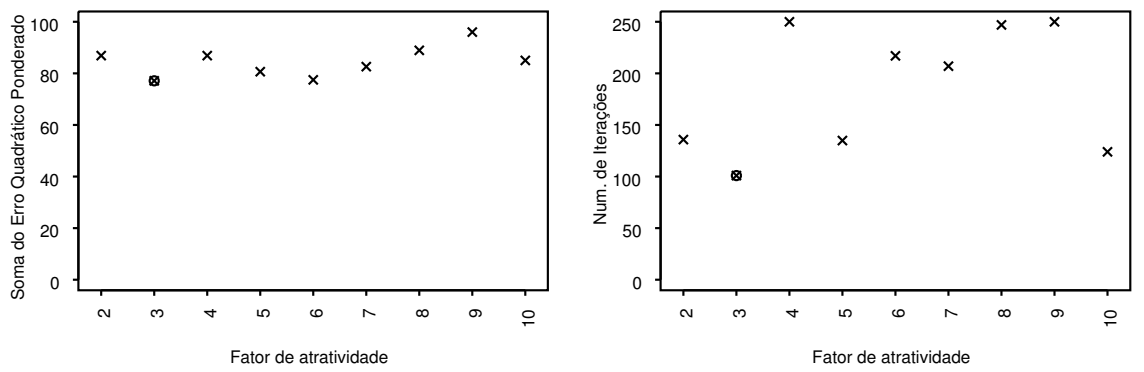

Figura 6: Simulações do AG para diferentes valores de $\alpha$ para o dia 30/12/2010 (curva de cupom de IPCA)

\section{Mutação}

O operador de mutação entra em ação logo após o operador de recombinação, com o objetivo de evitar que a solução do problema evolua para um ótimo local. Para isso, ele introduz variações aleatórias nos genes dos cromossomos e testa a qualidade dos cromossomos mutantes.

Cada gene $\left(\beta_{j, i}^{k+1}\right.$ e $\left.\lambda_{j, i}^{k+1}\right)$ de cada cromossomo $\left(\bar{\phi}_{i}^{k+1}\right)$ da recém-criada nova geração $(k+1)$ pode sofrer uma mutação com probabilidade $\pi$. Quando a mutação acontece, uma variável aleatória $\varepsilon_{j, i}^{k} \sim N\left(0, \sigma_{j}^{k}\right)$ é adicionada ao gene $j$ do cromossomo $i$. A qualidade dos cromossomos mutantes é testada e a lista de cromossomos da geração $(k+1)$ é reordenada, sendo que para os cromossomos sobreviventes da geração anterior $\left\{\bar{\phi}_{1}^{k+1}, \bar{\phi}_{2}^{k+1}, \ldots, \bar{\phi}_{M}^{k+1}\right\}$, a mutação só terá efeito se o cromossomo mutante tiver melhor qualidade que o cromossomo original.

A cada novo cromossomo gerado, o AG testa se ele satisfaz as condições de viabilidade expressas em (13), e caso contrário, seleciona novos cromossomos progenitores para gerar um novo cromossomo filho, repetindo o processo até que se obtenha um total de $N$ cromossomos viáveis na geração $k+1$ $:\left\{\bar{\phi}_{1}^{k+1}, \bar{\phi}_{2}^{k+1}, \ldots, \bar{\phi}_{M}^{k+1}, \bar{\phi}_{M+1}^{k+1}, \ldots, \bar{\phi}_{N}^{k+1}\right\}$.

\footnotetext{
${ }^{49} \mathrm{O}$ valor selecionado para $\alpha$ (após as simulações) foi de 3 para a curva de cupom de IPCA.
} 
A ocorrência de mutação em diferentes genes de um mesmo cromossomo são eventos estatisticamente independentes, de maneira que um dado cromossomo pode sofre mutação em zero, um, dois, três... genes. Um valor baixo de $\pi$ pode aumentar o risco de falsa convergência do algoritmo, enquanto que um valor alto de $\pi$ pode tornar o processo de convergência muito lento e até incerto.

Foram realizadas simulações do AG para diferentes valores de $\pi$, e o valor selecionado para a construção de cada curva de juros levou em conta o valor ótimo da função objetivo (valor mínimo da soma dos quadrados dos erros) e o número de iterações (gerações) necessárias para o alcance do mínimo. Como ilustração, o valor de $\pi$ para curva de cupom de IPCA $^{50}$ foi selecionado a partir das simulações apresentadas na Figura 7
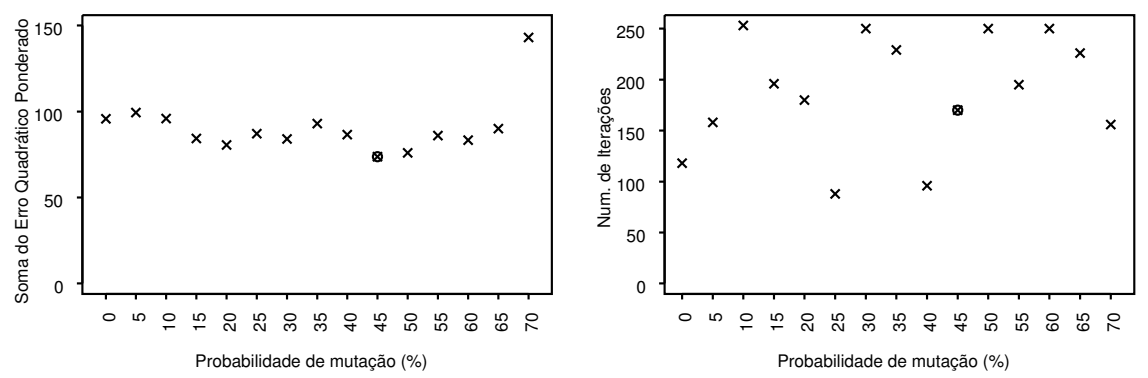

Figura 7: Simulações do AG para diferentes valores de $\pi$ para o dia 30/12/2010 (curva de cupom de IPCA)

Pode-se fazer a magnitude de cada mutação aumentar com o número de iterações (gerações) com o objetivo de impedir que o AG fique "preso" em uma região de mínimo local. Neste trabalho, optou-se por fazer o desvio padrão do termo aleatório que é somado ao gene mutante aumentar em $1 \%$ a cada iteração. Ou seja:

$$
\begin{gathered}
\sigma_{j}^{k}=\sigma_{j}^{k-1} .(1,01), \quad j=0, \ldots, 5 \\
k=1,2, \ldots
\end{gathered}
$$

Portanto, uma forma alternativa de se representar o cromossomo $i$ da geração $k$, muito usada no ramo (mais amplo) de algoritmos evolucionários, é através de um par de vetores:

$$
\overline{\bar{v}}_{i}^{k}=\left(\bar{\phi}_{i}^{k}, \bar{\sigma}_{i}^{k-1}\right)
$$

Onde:

- $\bar{\phi}_{i}^{k}$ representa um ponto no espaço de busca da solução ótima, e

- $\bar{\sigma}_{i}^{k-1}$ é um vetor de desvio padrão ${ }^{51}$ calculado iterativamente (equação (22))

As simulações do AG demonstradas nas Figuras 3, 4, 6 e 7 tiveram por objetivo, respectivamente, encontrar os valores de $\sigma, \eta, \alpha$ e $\pi$, que geram

\footnotetext{
${ }^{50} \mathrm{O}$ valor selecionado para $\pi$ (após as simulações) foi de $45 \%$ para a curva de cupom de IPCA.

${ }^{51}$ Usado para inicializar a população (quando $k=1$ ), conforme apresentado na equação (17), e para especificar a magnitude de cada mutação (quando $k \geq 2$ ), conforme a equação (22).
} 
o menor valor da função objetivo (dado pelas equações (14) e (15)) em um número razoável de iterações (inferior a 250). Pequenas variações dos parâmetros não alteram o resultado final da combinação de algoritmo genético e método Quasi-Netwon; ou seja, pequenas alterações nos parâmetros não afetam a capacidade de o algoritmo genético chegar até a região de mínimo global da função objetivo. Para cada simulação, apenas um dos parâmetros do AG foi modificado, permanecendo todos os outros parâmetros fixos; como vetor inicial de parâmetros, partiu-se dos valores ótimos encontrados por Gimeno \& Nave $(2006)^{52}$.

\section{Critério de parada}

Uma vez completada uma evolução geracional, e após testar a viabilidade de cada novo cromossomo, o AG repete iterativamente os processos de seleção, recombinação e mutação até atingir um "estágio estacionário" para a evolução da espécie (quando novas gerações não são capazes de introduzir melhorias genéticas na espécie) alcançando o ponto (ou região ${ }^{53}$ ) de ótimo global.

O critério de parada adotado neste trabalho foi a obtenção de uma série de 100 gerações (iterações do algoritmo) sem mudança em nenhum dos genes (parâmetros) do cromossomo (solução candidata) de melhor qualidade (menor valor da função objetivo). O algoritmo genético é usado como um préprocessador para realizar uma busca inicial sobre o ponto/região de mínimo global, e, posteriormente, a solução ótima obtida com o AG é usada como solução inicial em um algoritmo tradicional de otimização não linear (QuasiNewton) para o alcance do mínimo local dentro da região de mínimo global.

\section{Análise de resultados para a curva de cupom de IPCA}

Nesta seção, são apresentados os resultados detalhados da estimação do modelo de Svensson para a curva de cupom de IPCA, incluindo análise de erros, interpolação e extrapolação da curva, e a evolução histótica dos parâmetros. Os resultados (resumidos) da estimação para as demais curvas de juros estão mostrados no anexo do trabalho.

\subsection{Estimação da curva de cupom de IPCA, análise de erros e interpolação}

A curva de cupom de IPCA foi estimada para o último dia útil de cada mês, entre os meses de setembro de 2003 e dezembro de 2010 (um total de 88 meses). Para cada um desses dias (ou seja, para cada data de pregão, $t$ ), os parâmetros do modelo de Svensson foram estimados por meio de uma combinação dos métodos de algoritmo genético (AG) e Quasi-Newton $(\mathrm{QN})$, obtendo-se os estimadores de mínimos quadrados $\hat{\beta}_{0, t}, \hat{\beta}_{1, t}, \hat{\beta}_{2, t}, \hat{\beta}_{3, t}, \hat{\lambda}_{1, t}$ e $\hat{\lambda}_{2, t}$.

A estimativa da taxa à vista anual composta continuamente em $t$ para $\mathrm{o}$ prazo $\tau$ pode ser obtida a partir da equação (12):

\footnotetext{
${ }^{52}$ Vale ressaltar que o algoritmo genético desenvolvido para este trabalho introduziu um novo operador de mutação, diferente do proposto por Gimeno \& Nave (2006), e novos parâmetros de inicialização.

${ }^{53}$ Conforme dito anteriormente, os algoritmos evolucionários podem apresentar dificuldades para encontrar o ponto de mínimo local dentro da região de mínimo global (realização do "ajuste fino local"). Por isso, neste trabalho, foi usada uma combinação do algoritmo genético com um algoritmo tradicional de otimização (Quasi-Newton).
} 


$$
\begin{aligned}
\hat{y}_{t}(\tau) & =\hat{\beta}_{0, t}+\hat{\beta}_{1, t} \cdot\left(\frac{1-e^{-\hat{\lambda}_{1, t} \cdot \tau}}{\hat{\lambda}_{1, t} \cdot \tau}\right)+\hat{\beta}_{2, t} \cdot\left(\frac{1-e^{-\hat{\lambda}_{1, t} \cdot \tau}}{\hat{\lambda}_{1, t} \cdot \tau}-e^{-\hat{\lambda}_{1, t} \cdot \tau}\right) \\
& +\hat{\beta}_{3, t} \cdot\left(\frac{1-e^{-\hat{\lambda}_{2, t} \cdot \tau}}{\hat{\lambda}_{2, t} \cdot \tau}-e^{-\hat{\lambda}_{2, t} \cdot \tau}\right)
\end{aligned}
$$

A taxa à vista discreta composta anualmente é obtida a partir da equação (3):

$$
\hat{R}_{t, t+\tau}^{t}=\exp \left(\hat{y}_{t}(\tau)\right)-1
$$

Para a data de 30/12/2010, os estimadores dos parâmetros do modelo de Svensson obtidos pela combinação dos métodos de algoritmo genético e QuasiNewton para a curva de cupom de IPCA foram os seguintes:

$$
\begin{array}{cl}
\hat{\beta}_{0}=0,04829, & \hat{\beta}_{1}=-0,03660, \quad \hat{\beta}_{2}=0,07895, \quad \hat{\beta}_{3}=0,02163 \\
& \hat{\lambda}_{1}=1,876257, \quad \hat{\lambda}_{2}=0,19271
\end{array}
$$

A evolução do somatório do erro quadrático ponderado obtido com a estimação da ETTJ, usando cada método de estimação (somente o método de otimização Quasi-Newton (QN), e uma combinação de algoritmo genético e Quasi-Newton (AG e QN)), ao longo dos seis últimos meses anteriores à data de calibragem do AG (30/12/2010), está demonstrada na Figura 8. A evolução do erro médio quadrático ponderado (igual à soma do erro quadrático ponderado dividido pelo número de títulos públicos comercializados em cada data de pregão), ao longo de toda a série histórica de dados (de setembro de 2003 até dezembro de 2010) é apresentada na Figura 9.

O método combinado AG e QN mostrou-se consistentemente superior ao método tradicional de estimação $\mathrm{QN}$, sendo que, em algumas datas específicas, a aplicação do AG permitiu melhorar significativamente o resultado da estimação. Isso porque, ao se empregar o AG como um pré-processador para a busca inicial do ponto/região de ótimo global e, posteriormente, o método Quasi-Newton para a busca do ótimo local/global, evita-se "saltos" entre mínimos locais, obtendo assim um melhor ajuste da curva aos dados de mercado. ${ }^{54}$

A interpolação da ETTJ é resultado da substituição dos valores estimados dos parâmetros do modelo de Svensson na equação que define a taxa de juros à vista (equação (12)) para prazos de maturidade dentro da faixa de prazos constantes da base de dados. As ETTJs geradas por cada método de estimação ${ }^{55}$, para a data de pregão de 30/12/2010 e para os prazos de 6 meses até 40 anos, estão demonstradas na Figura 10, juntamente com as taxas à vista observadas, obtidas com a aplicação de técnica de bootstrapping ${ }^{56}$.

\footnotetext{
${ }^{54}$ A calibragem dos parâmetros do $\operatorname{AG}(\sigma, \eta, \alpha, \pi)$ foi feita para a data de pregão de 30/12/2010, um dos períodos em que se observa melhora significativa na estimação do modelo.

${ }^{55}$ As taxas contínuas foram convertidas para taxas discretas anuais.

${ }^{56}$ A técnica de bootstrapping consiste em tratar os títulos com cupom, como sendo combinações de títulos zero-cupons isolados e, dessa forma, determinar, através de técnicas recursivas, a taxa à vista (spot) para diferentes prazos de maturidade.
} 


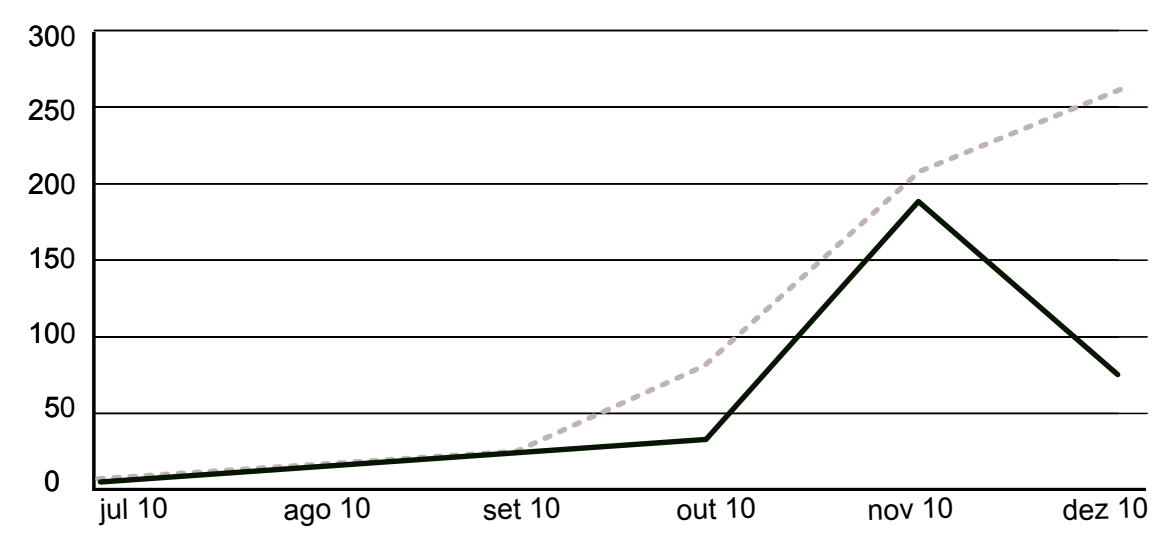

Combinação AG e QN . . . . . Q Quasi-Newton

Figura 8: Comparação do somatório do erro quadrático ponderado nos 6 meses anteriores à data de calibragem do modelo

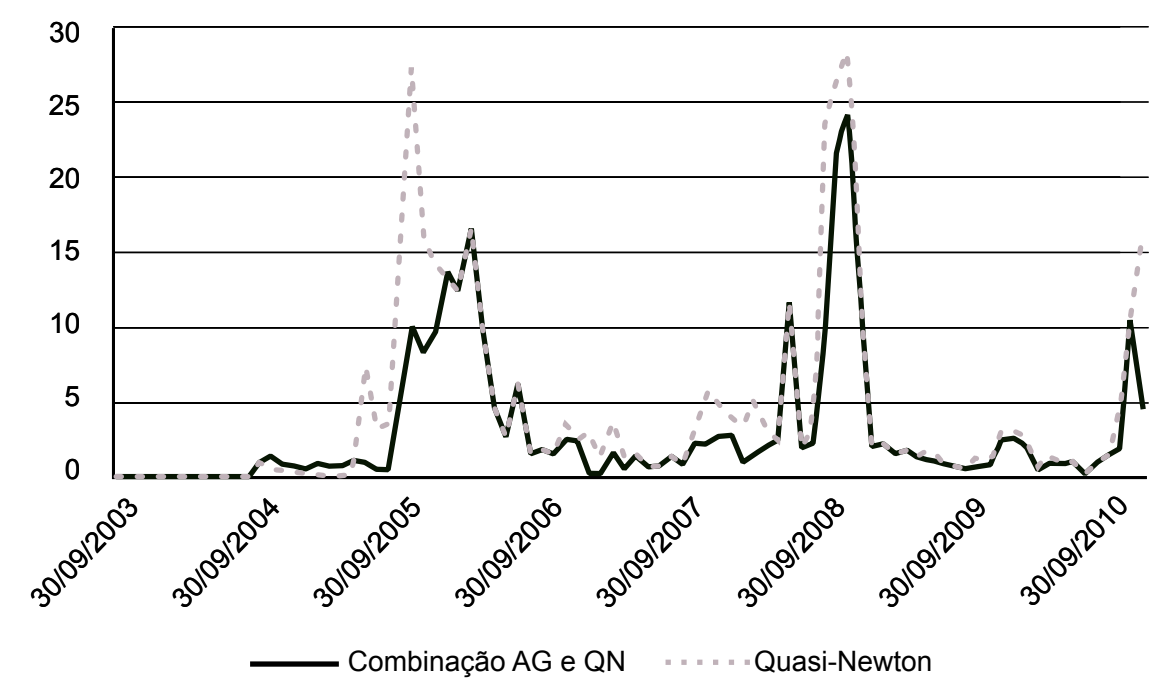

Figura 9: Comparação do erro médio quadrático ponderado ao longo de toda a série histórica de dados 
Nota-se que a aplicação do AG permite melhorar significativamente o ajuste da curva de juros aos dados de mercado. Além disso, a ponderação do erro quadrático de cada título pelo inverso da duration tornou os resíduos das taxas à vista homocedásticos (conforme antecipado na seção 4).

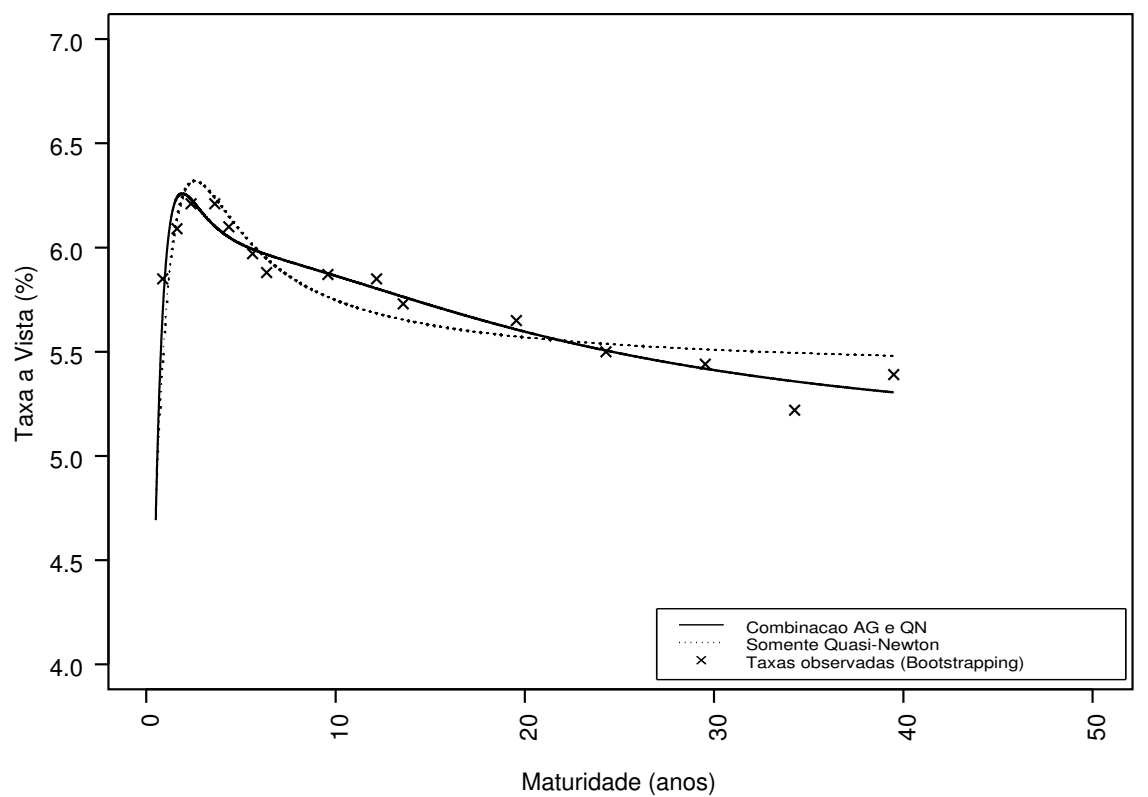

Figura 10: Interpolação das ETTJs geradas por cada método de estimação e as taxas à vista observadas para cada prazo de maturidade (para a data de pregão de $30 / 12 / 2010)$

A evolução histórica e a volatilidade das taxas à vista discretas para os prazos de 6 meses, 5 anos, 10 anos e 50 anos (para este último, taxas extrapoladas ${ }^{57}$ ) estão ilustradas, respectivamente, na Figura 11 e na Tabela 1. Há um "pico" em todas essas taxas no período entre setembro de 2008 e janeiro de 2009, período em aconteceu a crise dos subprimes (um desdobramento da crise financeira internacional, precipitada pela falência do banco de investimento Lehman Brothers (EUA)).

Para o cálculo da volatilidade, usa-se um estimador não tendencioso do desvio padrão da taxa à vista discreta estimada para cada vértice ${ }^{58}$. Observase que a volatilidade da taxa à vista discreta, $R_{t, t+\tau}^{t}$, diminui com o aumento do prazo de maturidade $(\tau)$, o que é consistente com modelos teóricos de estrutura a termo bem conhecidos (Vasicek 1977). Esses modelos mostram que a taxa a termo de longo prazo deve convergir para um determinado "valor limite" (e a volatilidade das taxas deve convergir para zero) quando o prazo tende ao infinito. No caso do modelo de Svensson, a taxa a termo de longo prazo pode ser obtida tomando-se o limite $\lim _{\tau \rightarrow \infty} y_{t}(\tau)=\beta_{0, t}$, e para a data de pregão de 30/12/2010, tem-se: $\hat{y}_{30 / 12 / 2010}(\infty)=4,83 \%$ (taxa contínua) e, portanto, $\hat{R}_{30 / 12 / 2010, \infty}=4,95 \%$ (taxa discreta).

\footnotetext{
${ }^{57}$ Conforme descrito na seção 5.2 .

${ }^{58} \mathrm{O}$ desvio padrão é calculado para a curva de juros do modelo, visto que, para diferentes datas de pregão, as maturidades dos títulos usados para construção de cada curva de juros são diferentes.
} 
Tabela 1: Volatilidade das taxas à vista discretas para os prazos de 6 meses, 5 anos, 10 anos e 50 anos.

\begin{tabular}{ccccc}
\hline Data & 0.5 ano & 5 anos & 10 anos & 50 anos \\
\hline Volatilidade (taxa unitária) & 0.02097 & 0.01249 & 0.00964 & 0.00883 \\
\hline
\end{tabular}

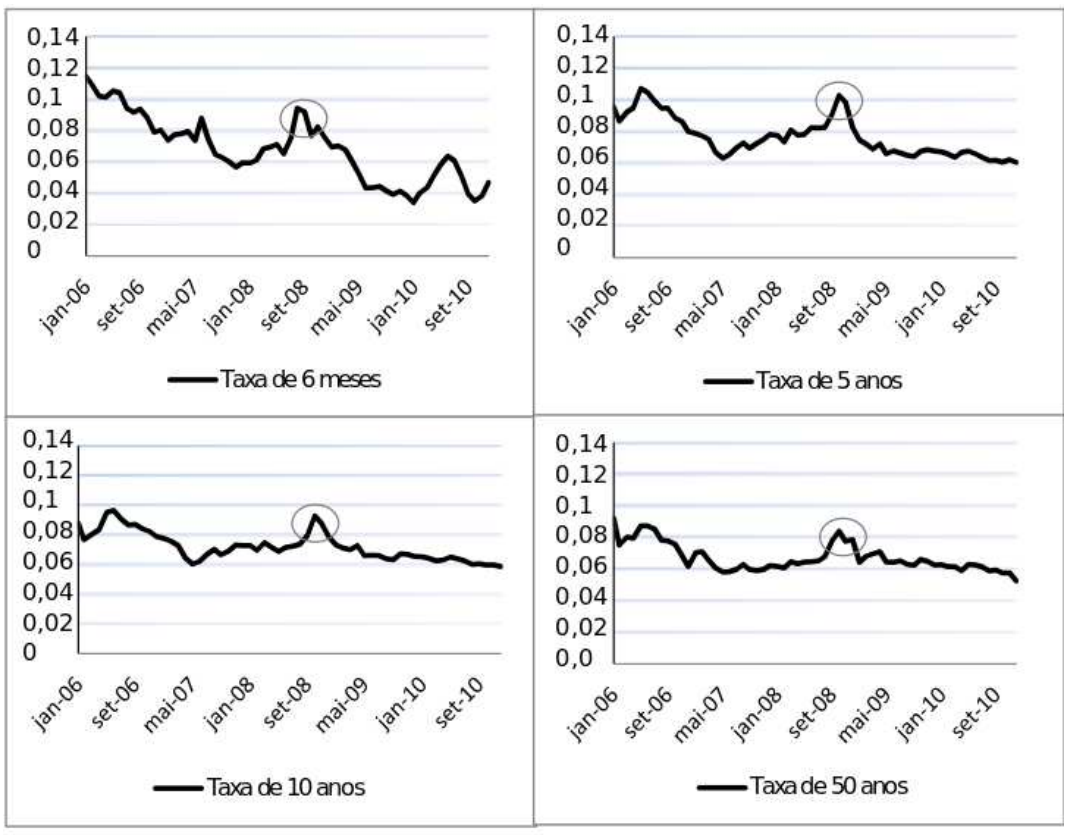

Figura 11: Evolução histórica e volatilidade das taxas à vista (discretas) para os prazos de $0.5,5,10$ e 50 anos

\subsection{Extrapolação da curva de cupom de IPCA}

A existência de compromissos de longo prazo das sociedades seguradoras e EAPCs (com prazos superiores aos maiores prazos de títulos públicos correntemente oferecidos no mercado) impõe a necessidade de que as ETTJs sejam extrapoladas. Estudos anteriores no Brasil (Varga 2009) mostram que muitos dos modelos comumente usados para a interpolação da estrutura a termo não permitem fazer uma extrapolação razoável (no sentido econômico), porque eventualmente levam a taxas indefinidamente crescentes ou negativas, esse sendo o caso, por exemplo, dos modelos de spline cúbico, exponencial e interpolação linear simples; já os modelos de suavização de taxas a termo (Nelson-Siegel e Svensson) e flat forward não levam a taxas à vista grandes ou negativas, sendo, portanto, possíveis de serem usadas para a extrapolação da estrutura a termo ${ }^{59}$.

A literatura internacional sugere ainda outros métodos de interpolação e extrapolação da ETTJ, com especial destaque para os métodos propostos por Barrie \& Hibbert (2008) e Smith \& Wilson (2001), onde o primeiro aplica spline cúbico para a parte líquida e Nelson-Siegel para a parte extrapolada

\footnotetext{
${ }^{59}$ Por exemplo, os bancos centrais europeu e brasileiro usam, respectivamente, os modelos de Svensson e flat forward para a extrapolação da ETTJ.
} 
da estrutura a termo, e o segundo modela a função desconto $\left(P_{t}(\tau)\right)$ como uma soma de funções exponenciais (ou funções kernel). Estes dois métodos dependem da especificação de uma "taxa a termo de longuíssimo prazo" (ou ultimate forward rate (UFR)) para a extrapolação da curva de juros.

A UFR é, por definição, a taxa a termo implícita na ETTJ livre de risco para a maturidade infinita (ou muito longa), e deve ser determinada por meio de métodos macroeconômicos. Os fatores macroeconômicos mais importantes usados para explicar as taxas a termo de longo prazo são a inflação esperada de longo prazo e a taxa de juros real esperada de longo prazo. Do ponto de vista teórico, pode-se ainda afirmar que há, pelo menos, dois outros componentes: o prêmio a termo nominal e efeito convexidade nominal esperados de longo prazo. A adoção de premissas sobre essas expectativas no Brasil, para um futuro tão distante, pode ser bastante controversa.

Neste trabalho, optamos por usar uma abordagem uniforme para interpolação e extrapolação da ETTJ (com o modelo de Svensson), e assim evitar o uso de uma variável macroeconômica exógena ao modelo, cuja especificação seria um tanto quanto controversa e arbitrária. Então, a extrapolação foi realizada por meio do modelo de Svensson, cujos parâmetros foram estimados pela combinação dos métodos de algoritmo genético e Quasi-Newton.

A extrapolação da ETTJ para além do último vértice disponível na base de dados (com suficiente liquidez) está demonstrada na Figura 12, para o dia $30 / 12 / 2010$. Nota-se que, pelos resultados das taxas extrapoladas até o prazo de 50 anos, ilustradas na Figura 12, e pela análise da volatilidade apresentada na seção anterior, o modelo proposto neste artigo mostra-se apropriado para a extrapolação da ETTJ.

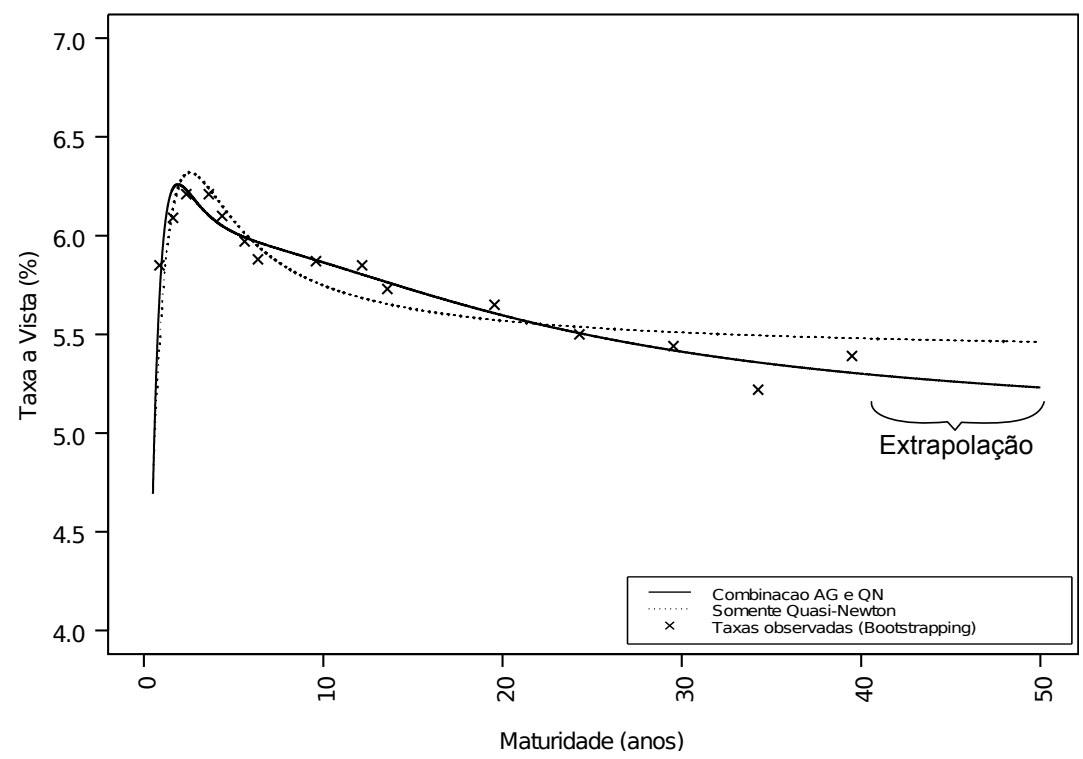

Figura 12: Extrapolação das ETTJs geradas por cada método de estimação e as taxas à vista observadas para cada prazo de maturidade (para a data de pregão de 30/12/2010)

É apresentada na Tabela 2, a ETTJ livre de risco de cupom de IPCA, na data de 30/12/2010, calculada a partir dos estimadores obtidos e extrapolada 
até o prazo de $50 \operatorname{anos}^{60}$.

Tabela 2: Taxas discretas anuais estimadas para a data de pregão de 30/12/2010.

\begin{tabular}{cccccc}
\hline anos & taxa $\%$ & anos & taxa $\%$ & anos & taxa $\%$ \\
\hline 0.5 & 4.69 & 17 & 5.67 & 34 & 5.36 \\
1 & 5.88 & 18 & 5.65 & 35 & 5.35 \\
2 & 6.26 & 19 & 5.62 & 36 & 5.34 \\
3 & 6.16 & 20 & 5.60 & 37 & 5.33 \\
4 & 6.07 & 21 & 5.57 & 38 & 5.32 \\
5 & 6.02 & 22 & 5.55 & 39 & 5.31 \\
6 & 5.98 & 23 & 5.53 & 40 & 5.30 \\
7 & 5.95 & 24 & 5.51 & 41 & 5.29 \\
8 & 5.92 & 25 & 5.49 & 42 & 5.28 \\
9 & 5.89 & 26 & 5.48 & 43 & 5.28 \\
10 & 5.86 & 27 & 5.46 & 44 & 5.27 \\
11 & 5.84 & 28 & 5.44 & 45 & 5.26 \\
12 & 5.81 & 29 & 5.43 & 46 & 5.26 \\
13 & 5.78 & 30 & 5.41 & 47 & 5.25 \\
14 & 5.75 & 31 & 5.40 & 48 & 5.24 \\
15 & 5.72 & 32 & 5.39 & 49 & 5.24 \\
16 & 5.70 & 33 & 5.37 & 50 & 5.23 \\
\hline
\end{tabular}

\subsection{Evolução histórica dos parâmetros do modelo de Svensson}

O uso de algoritmos genéticos, em complemento aos algoritmos tradicionais de otimização não linear, resultou em estimadores para os parâmetros do modelo de Svensson mais estáveis ao longo do tempo. Esse resultado torna-se particularmente importante quando se deseja interpretar economicamente os valores estimados dos parâmetros do modelo de Svensson. ${ }^{61}$

As evoluções históricas dos estimadores obtidos com a combinação de algoritmo genético e Quasi-Newton (AG e QN) e apenas com o método de otimização Quasi-Newton (QN) estão demonstradas nas Figuras 13, 14, 15 e 16. A volatilidade dos estimadores obtidos por cada método é apresentada na Tabela 3. Nota-se que o método combinado AG e QN gerou séries bem mais estáveis para os estimadores dos fatores de nível $\left(\beta_{0, t}\right)$, inclinação $\left(\beta_{1, t}\right)$ e curvaturas $\left(\beta_{2, t}\right.$ e $\left.\beta_{3, t}\right)$, assim como para o conjunto de velocidades de decaimento $\left\{\lambda_{1, t}, \lambda_{2, t}\right\}$. Em particular, nota-se que os estimadores de $\beta_{2, t}$ e $\beta_{3, t}$ gerados pelo método QN apresentaram saltos opostos/espelhados que tendem a se cancelar para valores próximos de $\lambda_{1, t}$ e $\lambda_{2, t}$.

\footnotetext{
${ }^{60}$ Para maturidades superiores a 50 anos, pode-se ainda estimar as taxas de cupom de IPCA usando a equação (12) e substituindo os parâmetros do modelo pelos estimadores encontrados.

${ }^{61}$ Os fatores da estrutura a termo possuem a interpretação de nível (ou longo prazo), $\beta_{0, t}$, inclinação (ou curto prazo), $\beta_{1, t}$, e curvaturas (ou médio prazo), $\beta_{2, t}$ e $\beta_{3, t}$. Os parâmetros $\lambda_{1, t}$ e $\lambda_{2, t}$ caracterizam as velocidades de decaimento dos componentes de médio prazo da curva de juros.
} 


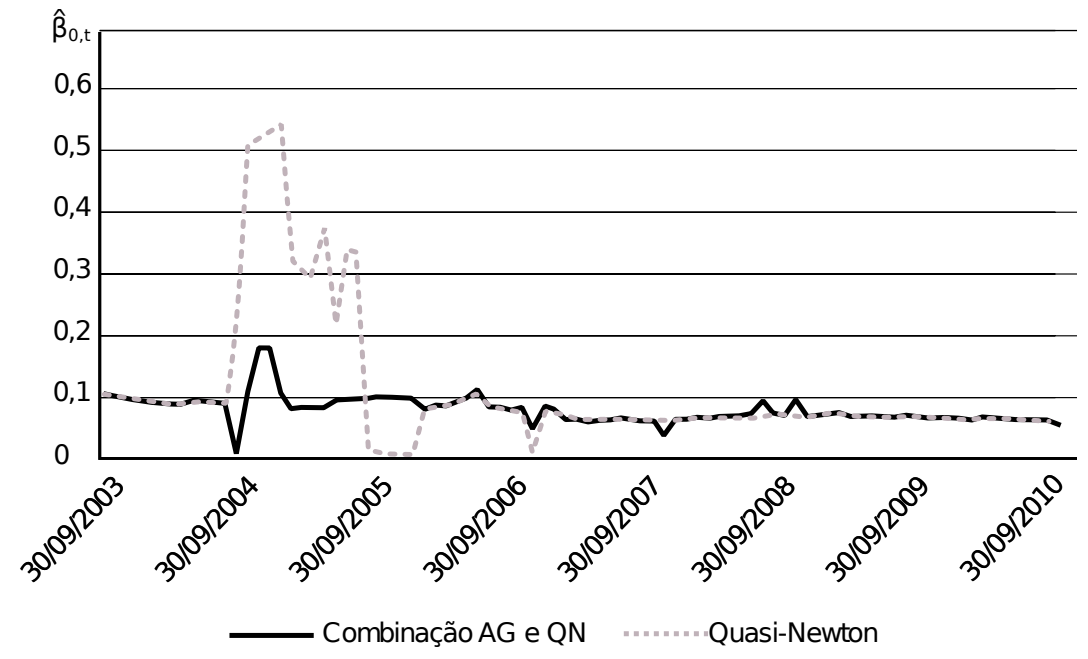

Figura 13: Evolução histórica de $\hat{\beta}_{0, t}$

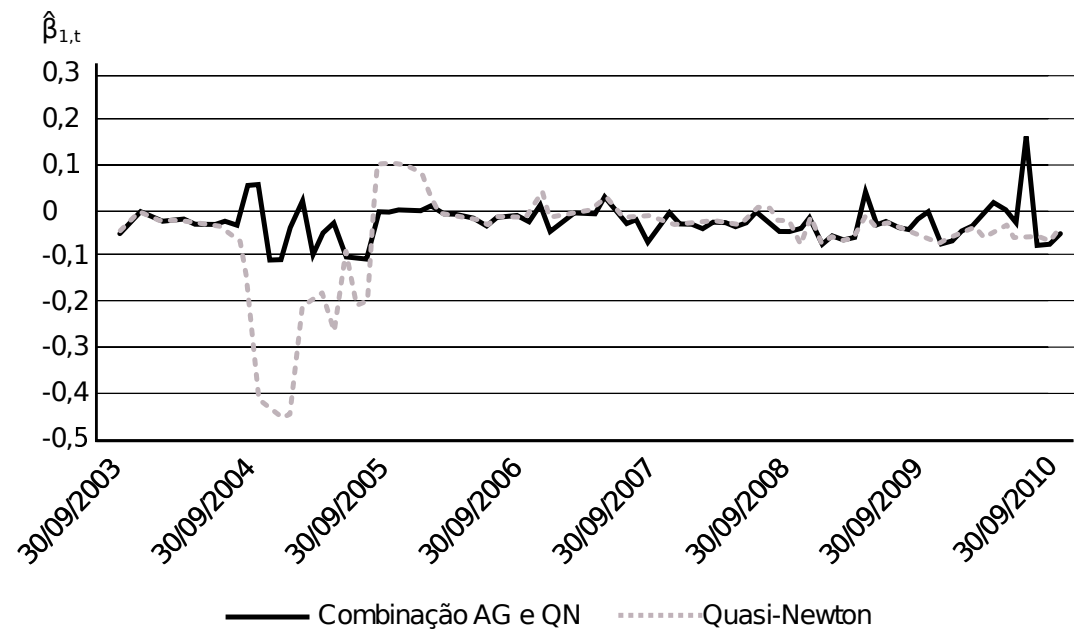

Figura 14: Evolução histórica de $\hat{\beta}_{1, t}$ 


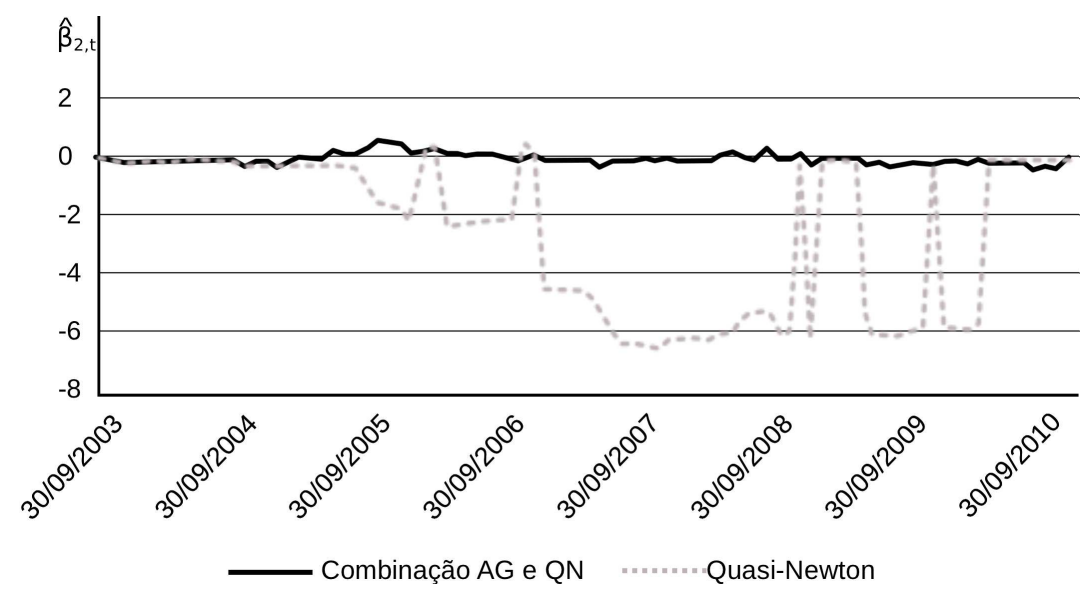

Figura 15: Evolução histórica de $\hat{\beta}_{2, t}$

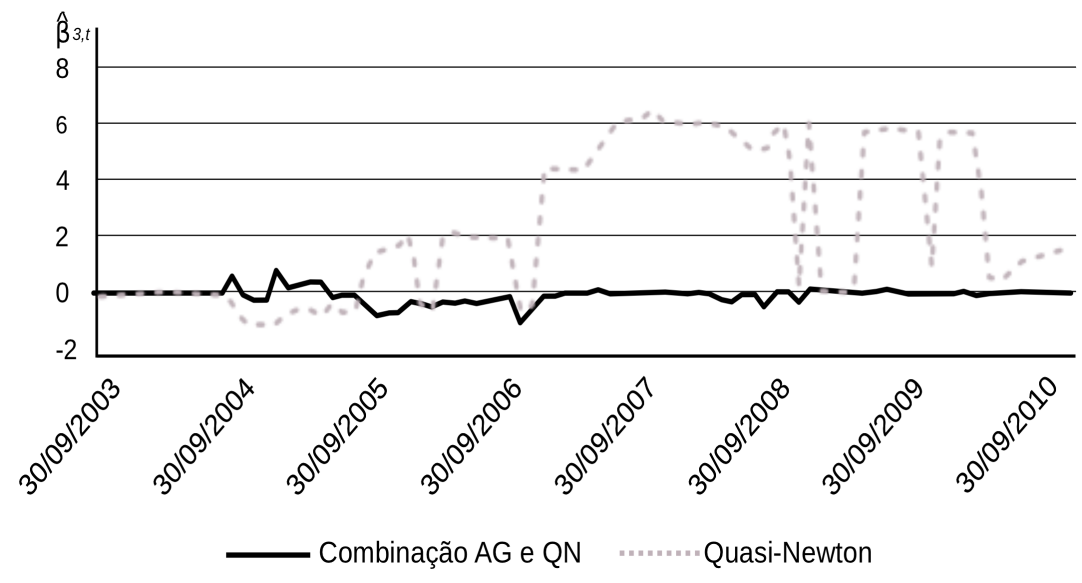

Figura 16: Evolução histórica de $\hat{\beta}_{3, t}$ 
Tabela 3: Volatilidade dos parâmetros obtidos com cada método de otimização.

\begin{tabular}{lcccccc}
\hline Volatilidade & $\hat{\beta}_{0, t}$ & $\hat{\beta}_{1, t}$ & $\hat{\beta}_{2, t}$ & $\hat{\beta}_{3, t}$ & $\hat{\lambda}_{1, t}$ & $\hat{\lambda}_{2, t}$ \\
\hline Quasi-Newton & 0,116 & 0,110 & 2,681 & 2,734 & 0,407 & 47,310 \\
Alg. Genético e Q.N. & 0,023 & 0,041 & 0,192 & 0,268 & 3,824 & 1,829 \\
\hline
\end{tabular}

\section{Conclusão}

Neste artigo, propomos um método de interpolação e extrapolação da ETTJ livre de risco (no Brasil) para as curvas de juros de taxas "pré", cupom cambial, cupom de IGPM, cupom de TR e cupom de IPCA.

A escolha da base de dados usada para cada curva de juros considera o instrumento financeiro livre de risco de maior liquidez no mercado, o número de vértices proporcionados por cada instrumento e o prazo do último ponto líquido de cada curva de juros. Dados de mercado foram coletados para o último dia útil de cada mês entre os meses de setembro de 2003 e dezembro de 2010. Para a estimação dos parâmetros do modelo foram usados um algoritmo tradicional de otimização não linear (Quasi-Newton) e um algoritmo genético especialmente desenvolvido para esta finalidade.

O artigo propõe o uso do modelo de Svensson (1994) para a interpolação e extrapolação da ETTJ livre de risco e o uso de algoritmos genéticos, em complemento aos algoritmos tradicionais de otimização não linear, para a estimação dos parâmetros do modelo, o que permite reduzir o risco de falsa convergência e gerar parâmetros com séries temporais mais estáveis. A análise dos resultados da estimação das curvas de juros mostra que, para a extrapolação considerada neste estudo, o modelo de Svensson é apropriado.

Com a divulgação deste trabalho, esperamos contribuir para que o mercado segurador brasileiro construa estimativas dos valores descontados dos seus fluxos de caixa de maneira consistente e coerente, a fim de mitigar os riscos, para os segurados e acionistas, decorrentes de uma má estimação de valores. O método aqui apresentado é de utilidade para o acompanhamento dos compromissos futuros das seguradoras, resseguradores locais e EAPCs, por meio do monitoramento das provisões e do cálculo dos capitais adicionais baseados em riscos.

\section{Agradecimentos}

Os autores agradecem os comentários e as sugestões do Editor e dos revisores da Revista Economia Aplicada que contribuíram para melhorar a qualidade do artigo. 


\section{Referências Bibliográficas}

Anbima (2010), 'Estrutura a termo das taxas de juros estimada e inflação implícita', Acessível em: http://www.andima.com.br/est_termo/arqs/esttermo_metodologia.pdf. Último acesso em 15 de março de 2011.

Arifovic, J. \& Gencay, R. (2000), 'Statistical properties of genetic learning in a model of exchange rate', Journal of Economic Dynamics and Control 24, 9811005.

Barrie \& Hibbert (2008), 'A framework for estimating and extrapolating the term structure of interest rates', Acessível em: http://www.barrhibb.com/documents/downloads/ A_Framework_for_Estimating_and_Extrapolating _the_Term_Structure.pdf. Último acesso em 15 de março de 2011.

Bertsekas, D. P. (1999), Nonlinear Programming, 2nd edn, Athena Scientific.

Chambers, D. R., Carleton, W. T. \& Waldman, D. M. (1984), 'A new approach to estimation of the term structure of interest rates', Journal of Financial and Quantitative Analysis 19(3), 233-252.

Davis, L. (1989), Adapting operator probabilities in genetic algorithms, in J. D. Schaffer, ed., 'Proceedings of the third international conference on genetic algorithms', Morgan Kaufmann Publishers, San Mateo.

Davis, L. (1991), Handbook of Genetic Algorithms, Van Nostrand Reinhold, New York.

Dawid, H. (1999), Adaptative learning by genetic algorithms: Analytical results and applications to economic models, 2nd edn, Springer, Berlin.

Diebold, F. X. \& Li, C. (2006), 'Forecasting the term structure of government bond yields', Journal of Econometrics 130(2), 337-364.

Eshelman, L. \& Shaffer, J. (1993), Real-coded genetic algorithms and interval schemata, in D. L.Whitley, ed., 'Foundations of Genetic Algorithms 2', Morgan Kaufmann Publishers, San Mateo.

Fabozzi, J. F. (2006), Bond Markets, Analysis and Strategies, 6th edn, Prentice Hall.

Fisher, M., Nychka, D. \& Zervos, D. (1995), 'Fitting the term structure of interest rates with smoothing splines', Working Paper 95-1, Finance and Economics Discussion Series, Federal Reserve Board.

Fraletti, P. B. (2004), 'Ensaios sobre taxas de juros em reais e sua aplicação na análise financeira', Tese (Doutorado) - FEA Universidade de São Paulo.

Gimeno, R. \& Nave, J. M. (2006), 'Genetic algorithm estimation of interest rate term structure', Madrid, Banco de España. Documentos de Trabajo, n. 0634 .

Herrera, F., Lozano, M. \& Verdegay, J. L. (1998), 'Tackling real-coded genetic algorithms: Operators and tools for behavioural analysis', Artificial Intelligence Review 12(4), 265-319. 
Holland, J. (1975), Adaptation in Natural and Artificial Systems, Ann Arbor: The University of Michigan Press.

Leite, A. L., Gomes, R. B. P. \& Valentim, J. M. V. (2009), 'Previsão da curva de juros: Um modelo estatístico com variáveis macroeconômicas', Departamento de Estudos e Pesquisas, Banco Central do Brasil.

Litzenberger, R. H. \& Rolfo, J. (1984), 'An international study of tax effects on government bonds', Journal of Finance 39(1), 1-22.

McCulloch, J. H. (1975), 'The tax-adjusted yield curve', Journal of Finance 30(3), 811-830.

Mitchell, M. (1998), An Introduction to Genetic Algorithms, 1st edn, The MIT Press, Cambridge (MA).

Nelson, C. R. \& Siegel, A. F. (1987), 'Parsimonious modeling of yield curves', The Journal of Business, University of Chicago Press 60(4), 473-489.

Ray, I. C. (1992), The Bond Market: Trading and Risk Management, McGrawHill.

Scott, E. C. (2009), Evolution vs. Creationism: An Introduction, 2nd edn, University of California Press.

Smith, A. \& Wilson, T. (2001), 'Fitting yield curves with long term constraints', Research Notes, Bacon and Woodrow.

Steven, L. A. \& Kleinstein, A. D. (1991), Valuing fixed-income investments and derivative securities: Cash-flow analysis and calculations, New York Institute of Finance.

SUSEP (2010), 'Circular susep 410, de 22 de dezembro de 2010, superintendência de seguros privados', Acessível em: http://susep.gov.br/bibliotecaweb/docOriginal.aspx?tipo $=1 \&-$ codigo $=27458$. Último acesso em 15 de março de 2011.

Svensson, L. E. O. (1994), 'Estimating and interpreting forward interest rates: Sweden 1992-1994', International Monetary Fund Working Paper, No. 114, Washington DC.

Varga, G. (2009), 'Teste de modelos estatísticos para a estrutura a termo no brasil', Revista Brasileira de Economia 63(4), 361-394.

Vasicek, O. (1977), 'An equilibrium characterization of the term structure', Journal of Financial Economics 5(8), 177-188.

Wright, A. (1991), Genetic algorithms for real parameter optimization, in G. J. E. Rawlin, ed., 'Foundations of Genetic Algorithms 1', Morgan Kaufmann Publishers, San Mateo. 


\section{Apêndice A Demais curvas de juros}

As curvas de taxas "pré", cupom de IGPM, cupom de TR e cupom cambial foram estimadas usando o mesmo procedimento aplicado para a curva de cupom de IPCA, e os resultados para a data de 30/12/2010 são apresentados nas Figuras A.1, A.2, A.3 e A.4. Para cada uma dessas curvas, foram realizadas simulações do algoritmo genético com o objetivo de encontrar os valores mais apropriados para os parâmetros de calibragem $(\sigma, \eta, \alpha$ e $\pi$ ) (aqueles que geram o menor valor da função objetivo associada a cada curva em um número razoável de iterações). Para as curvas de cupom de TR e cupom cambial, tendo em vista a relativa simplicidade dessas curvas e o risco de multicolinearidade, foi usado o modelo de Nelson e Siegel (um caso particular do modelo de Svensson quando $\beta_{3, t}=0$ ou $\lambda_{1, t}=\lambda_{2, t}$ ). Não foi feita qualquer extrapolação da curva de cupom cambial para além do último ponto líquido da curva ${ }^{62}$, haja vista não existir passivo em dólar no mercado segurador para prazo tão longo. As demais extrapolações obedecem a expectativa de longevidade dos compromissos referenciados a essas curvas.

Para as curvas onde a função objetivo que se quer minimizar é expressa em termos de taxas de juros (e não em termos de preços de títulos públicos), os resultados obtidos com a estimação da ETTJ usando uma combinação dos métodos de AG e QN apresentam ganhos pouco significativos em relação aos resultados obtidos usando somente o método QN. Por isso, estão demonstrados abaixo apenas os resultados da estimação usando AG e QN e as taxas à vista observadas (para a data de 30/12/2010).

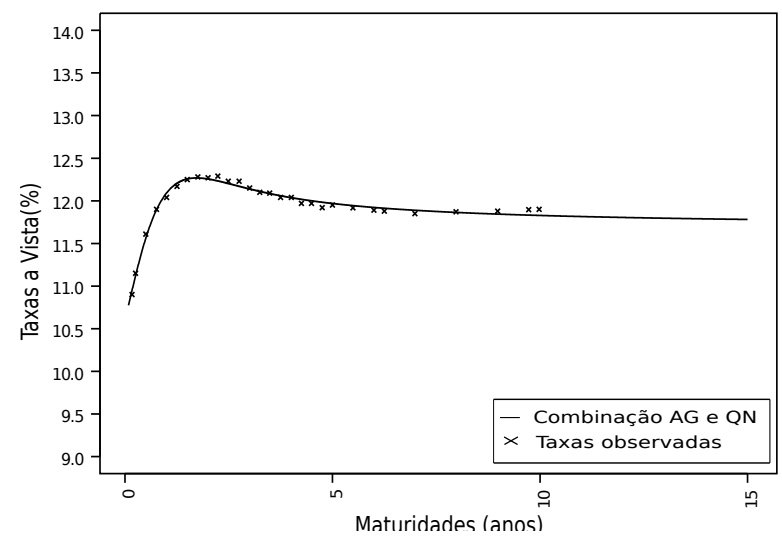

$$
\begin{aligned}
& \hat{\beta}_{0}=0,11054 \\
& \hat{\beta}_{1}=-0,00967 \\
& \hat{\beta}_{2}=-0,66457 \\
& \hat{\beta}_{3}=0,68617 \\
& \hat{\lambda}_{1}=2,34453 \\
& \hat{\lambda}_{2}=2,28612
\end{aligned}
$$

Figura A.1: Curva de taxas "pré" (para data 30/12/2010)

\footnotetext{
${ }^{62}$ Aqui considerado como líquido o último vencimento com mais de 100 contratos realizados.
} 


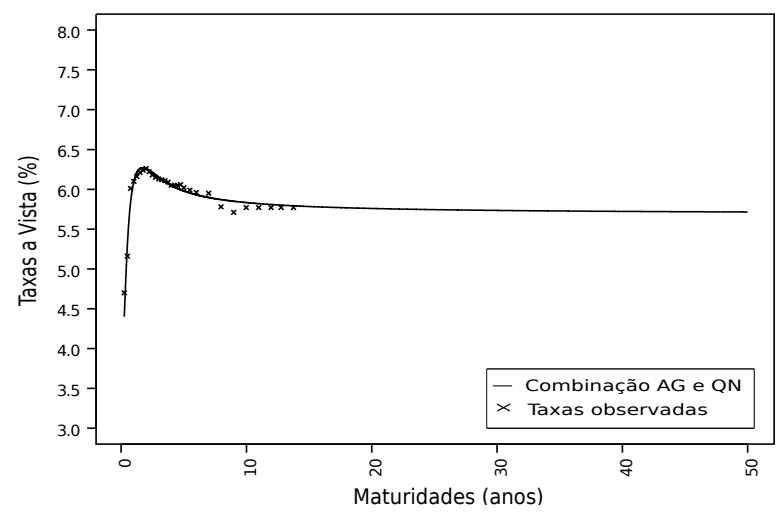

$$
\begin{aligned}
& \hat{\beta}_{0}=0,05530 \\
& \hat{\beta}_{1}=-0,00900 \\
& \hat{\beta}_{2}=-0,07376 \\
& \hat{\beta}_{3}=0,03288 \\
& \hat{\lambda}_{1}=10,7977 \\
& \hat{\lambda}_{2}=1,64954
\end{aligned}
$$

Figura A.2: Curva de cupom de IGPM (para data 30/12/2010)

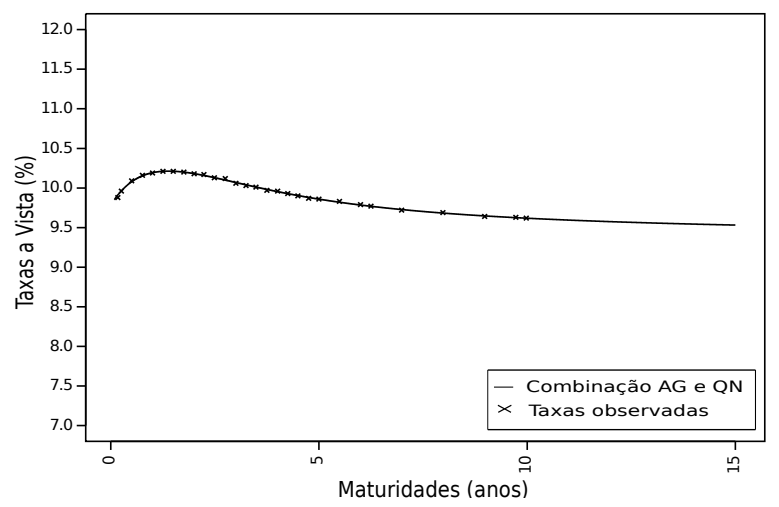

$\hat{\beta}_{0}=0,08946$

$\hat{\beta}_{1}=0,00389$

$\hat{\beta}_{2}=0,01949$

$\hat{\beta}_{3}=0$

$\hat{\lambda}_{1}=0,98726$

$\hat{\lambda}_{2}=0$

Figura A.3: Curva de cupom de TR (para data 30/12/2010) 


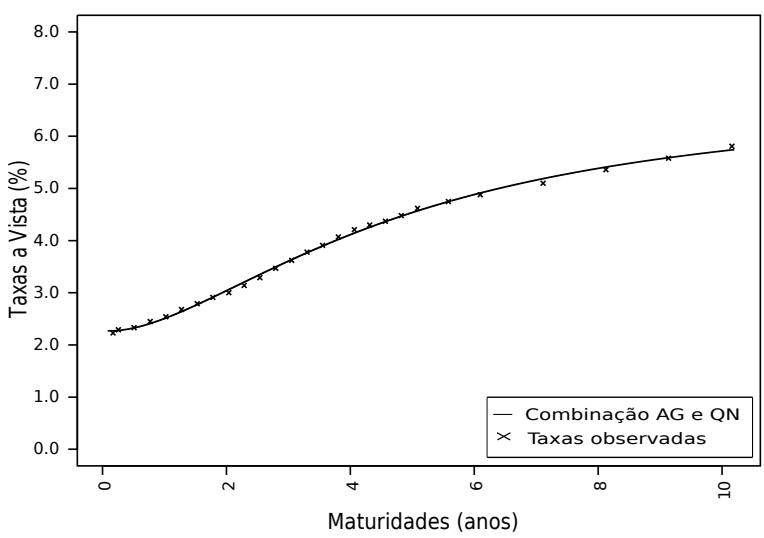

$$
\begin{aligned}
& \hat{\beta}_{0}=0,06882 \\
& \hat{\beta}_{1}=-0,04635 \\
& \hat{\beta}_{2}=-0,04866 \\
& \hat{\beta}_{3}=0 \\
& \hat{\lambda}_{1}=0,71603 \\
& \hat{\lambda}_{2}=0
\end{aligned}
$$

Figura A.4: Curva de cupom cambial (para data 30/12/2010) 